\title{
Structural Determinants of Improved Fluorescence in a Family of Bacteriophytochrome-based Infrared Fluorescent Proteins: Insights from Continuum Electrostatic Calculations and Molecular Dynamics Simulations.
}

\author{
Supplementary Information
}

\begin{abstract}
Mikolaj Feliks, ${ }^{1,2,3}$ Céline Lafaye, ${ }^{1,2,3}$ Xiaokun Shu, ${ }^{4,5}$ Antoine Royant, ${ }^{1,2,3,6, \dagger}$ Martin Field ${ }^{1,2,3, \dagger}$
\end{abstract}

1) Université Grenoble Alpes, IBS, F-38044 Grenoble, France

2) CNRS, IBS, F-38044 Grenoble, France

3) CEA, IBS, F-38044 Grenoble, France

4) Department of Pharmaceutical Chemistry, University of California, San Francisco, California 94158, USA

5) Cardiovascular Research Institute, University of California, San Francisco, California 94158, USA

6) European Synchrotron Radiation Facility, 6 Rue Jules Horowitz, Grenoble, 38043, France

†) to whom correspondence should be addressed; e-mail: antoine.royant@ibs.fr, martin.field@ibs.fr

July 18, 2016 


\section{Contents}

$\begin{array}{ll}\text { List of Figures } & 3\end{array}$

$\begin{array}{lc}\text { List of Tables } & 5\end{array}$

S1 Statistical distribution of the important dihedral angles of the chro$\begin{array}{ll}\text { mophore. } & 20\end{array}$

S2 Calculations of different protonation forms of biliverdin in the gas phase. 25

S3 Derivation of parameters for the deprotonated chromophore. $\quad 28$

S4 Chromophore dynamics and migration of water molecules in the situation at neutral $\mathrm{pH}$ and with the B-deprotonated chromophore.

$\begin{array}{ll}\text { References } & 49\end{array}$ 


\section{List of Figures}

S1 Sequence alignment between the chromophore-binding domain of the bacteriophytochrome from Deinococcus radiodurans DrCBD and infrared fluorescent proteins. . . . . . . . . . . . . . . . . . . . . 6

S2 Comparison between the chromophore environment in $\operatorname{Dr}$ CBD and IFP1.0. 7

S3 Experimental pH dependence of fluorescence for different IFPs. . . . . . . . 8

S4 Labeling of the important atoms and dihedral angles of the chromophore. . 9

S5 Time evolution of the root-mean-square deviations of the chromophore atoms. 10

S6 Titration curves for residues at the interface between the monomers, calculated using the structures of complete dimers. . . . . . . . . . . . . . . . 11

S7 Titration curves for residues at the interface between the monomers, calculated using the structures of monomers. . . . . . . . . . . . . . . . . 12

S8 Probabilities of occurrence of different protonation forms of His260, Asp207 and His207. . . . . . . . . . . . . . . . . . . . . . . . 13

S9 Statistical distributions of dihedral angles 1-3 of the chromophore for all proteins collected from molecular dynamics simulations. . . . . . . . . . . . 14

S10 Statistical distributions of dihedral angles 4-6 of the chromophore for all proteins collected from molecular dynamics simulations. . . . . . . . . . 15

S11 Statistical distributions of dihedral angles 1-3 of the chromophore for all proteins collected from molecular dynamics simulations. . . . . . . . . . . . 16

S12 Statistical distributions of dihedral angles 4-6 of the chromophore for all proteins collected from molecular dynamics simulations. . . . . . . . . . . 17

S13 Superposition of the calculated geometries of the fully protonated and Bdeprotonated chromophore. . . . . . . . . . . . . . . . . 27

S14 Energy profiles for rotations around the four dihedral angles of the chromophore. . . . . . . . . . . . . . . . . . 30 
S15 Topology file for biliverdin deprotonated at pyrrole ring B. . . . . . . . . . 31

S16 Parameter file for biliverdin deprotonated at pyrrole ring B. . . . . . . . . 35

S17 Statistical distributions of the six dihedral angles of the chromophore for all proteins collected from molecular dynamics simulations. . . . . . . . . . 45

S18 Mobility of water molecules inside the chromophore binding pocket at $\mathrm{pH}=7$ and with the B-deprotonated chromophore. . . . . . . . . . . 47 


\section{List of Tables}

S1 Distributions of the six dihedral angles for the fully protonated chromophore at neutral pH. . . . . . . . . . . . . . . . . . . . . . 18

S2 Distributions of the six dihedral angles for the fully protonated chromophore at low pH. . . . . . . . . . . . . . . . . . . . 19

S3 Distributions of the six dihedral angles for the chromophore deprotonated at the B pyrrole ring. . . . . . . . . . . . . . . . . . 46

S4 Animations showing key events during the molecular dynamics simulations. 48 

1
10
20
30
40
50

DICBD MSRD PLPFEP P LY LGGPEITTENCEREP I H I PGS I QP HGA L L T ADGHSGEVLQMS IFP10 MSRDPLPFFP LYLGGPEITTENCEREPIHIPGSIQPHGALLTADGHSGEVLQMS IFP11 MSRDPLPFEPPLYLGGPEITTENCEREPIHIPGSIQPHGALITADGHSGEVLQMS IFP12 MSRDPLPFEPPIYLGGPEITTENCEREPIHIPGSIQPHGALLTADGHSGEVLQMS IFP14 MARDPLPFEP LYLGGPEITTENCEREPIHIPGSIQPHGALITADGHSGEVLQVS IFP20 MARDPQPFFPPLYLGGPEITTENCEREPIHIPGSIQPHGALLTADGHSGEVLQVS

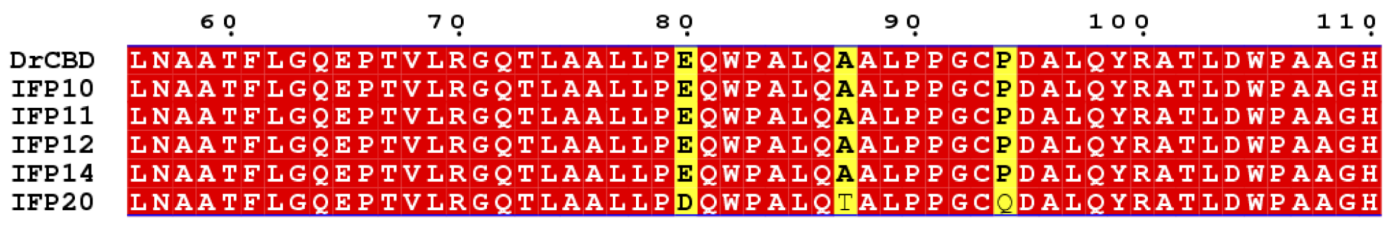

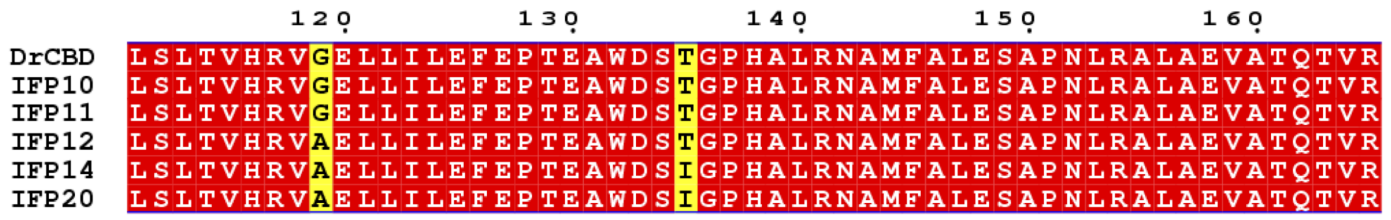

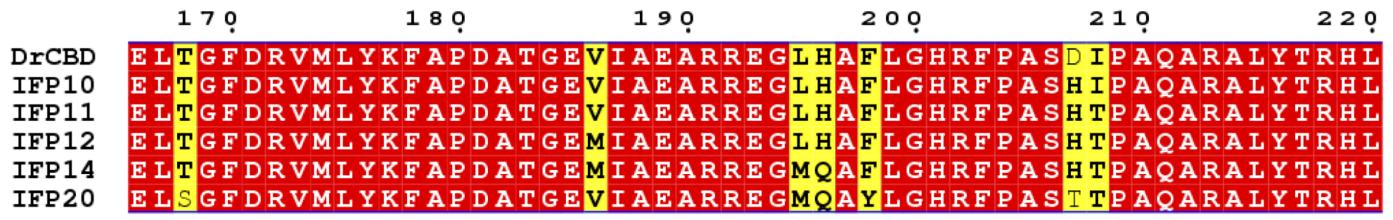
230
240
250
260
270

DrCBD LRLTADTRAAAVPLDPVLNPQTNAPTP LGGAVLRATSPMHMQYLRNMGVGSSLSV

IFP10 LRITADTRAAAVP LDPVINP QTNAPTP LGGAVLRATSPMHMQY LRNMGVGSSISV

IFP11 LRLTADTRAAAVPLDPVINP QTNAPTP L G GAVLRATSPMHMQYLRNMGVGSSLSV

IFP12 LRLTADTRAAAVPLDPVINPQTNAPTPLGGAVLRATSPMHMQYLRNMGVGSSISV

IFP14 LRLTADTRAAAVPLDPVLNP QTNAPTPLGGAVLRATSPMHMQYLRNMGVGSSLSV

IFP20 LRLTADTRAAAVPLDPVLNPQTNAPTPLGGAVLRATSPMHMQYLRNMGVGSSLSV
280
290
300
310
320

DrCBD SVVVGGQLWGLIACHHQTPYVLPP D LRTTLEYLGRLLSLQVQVEEA

IFP10 SVVVGGQLWGLIACHHQTPYVLPP DLRTTIEYLGRLLSLQVQVKEA

IFP11 SVVVGGQLWGLIVCHHQTPYVLPPDLRTTLEYLGRLLSLQVQVKEA

IFP12 SVVVGGQLWGLIVCHHQTPYVLPPDLRTT LEYLGRLLSLQVQVKEA

IFP14 SVVVGGQLWGLIVCHHQTPYVLPPDLRTTIEYLGRKLSGQVQRKEA

IFP20 SVVVGGQLWGLIVCHHQTPYVLPPDLRTTLEYLGRLLSLQVQRKEA

Figure S1: Sequence alignment between the chromophore-binding domain of the bacteriophytochrome from Deinococcus radiodurans DrCBD and infrared fluorescent proteins IFP1.0, IFP1.1, IFP1.2, IFP1.4 and IFP2.0. The alignment was performed via the ClustalW server ${ }^{1}$ and the figure was prepared with ESPript. ${ }^{2}$ 


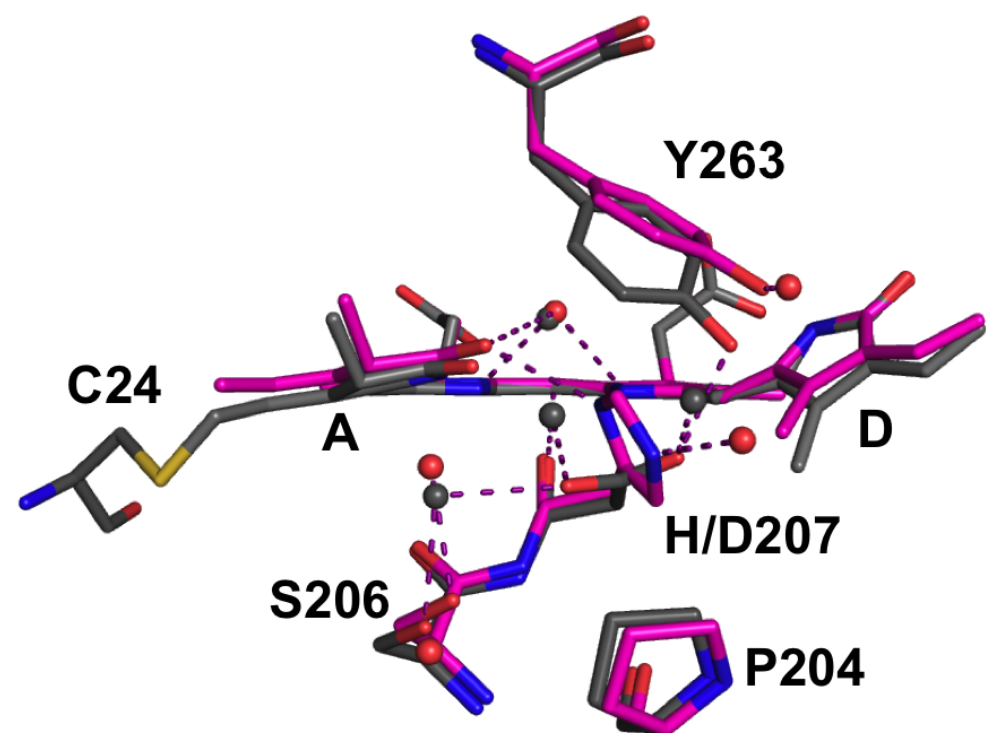

Figure S2: Comparison between the chromophore environment in $\operatorname{DrCBD}$ (PDB entry code: 2O9C, dark grey) and IFP1.0 (PDB entry code: 3S7O, magenta). The figure was prepared with PyMOL. ${ }^{3}$ 


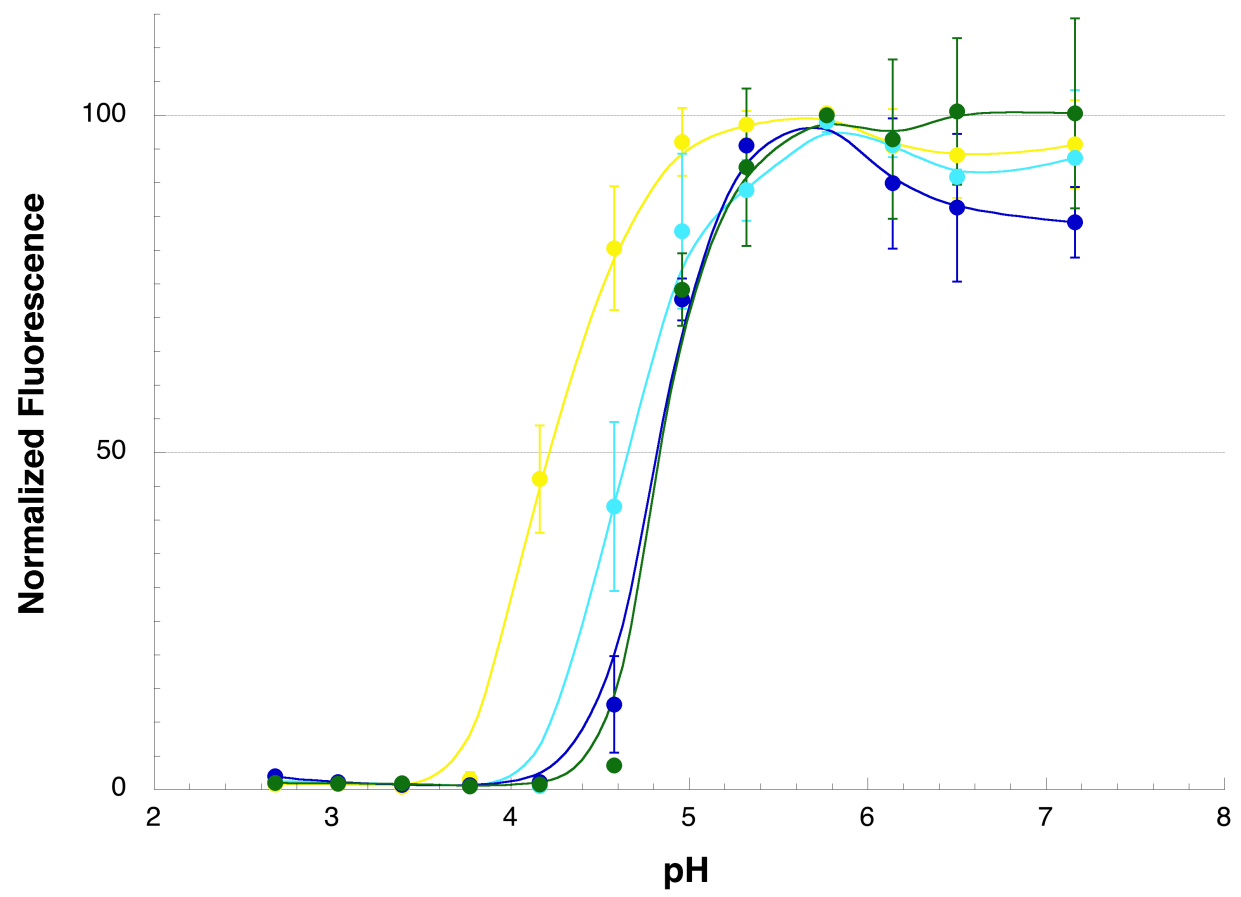

Figure S3: pH dependence of fluorescence for IFP1.1 (blue), IFP1.2 (green), IFP1.4 (cyan) and IFP2.0 (yellow). Fluorescence excitation was set at $640 \mathrm{~nm}$ and fluorescence emission was monitored between 660 and $800 \mathrm{~nm}$. 


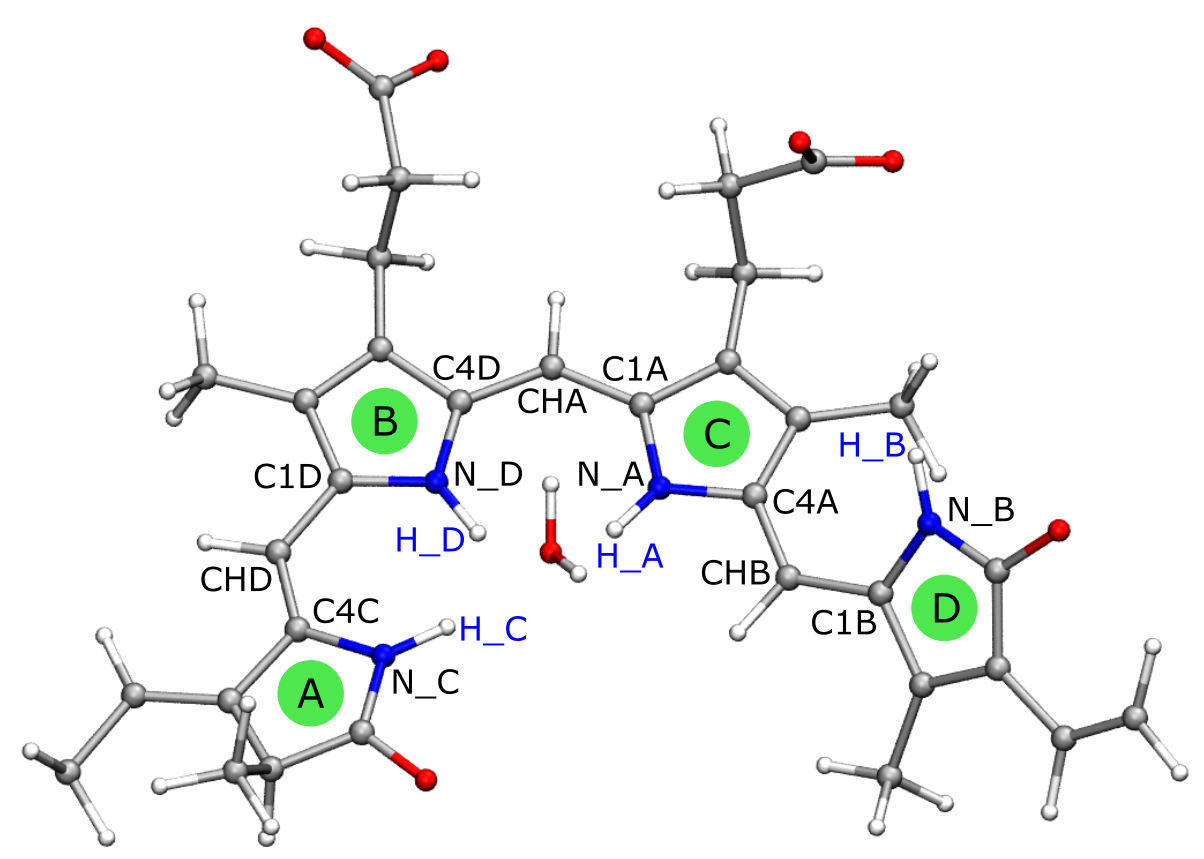

Figure S4: Fully protonated biliverdin chromophore as seen in the binding pocket of DrCBD. Important atoms discussed in the text are labeled. Hydrogens at titratable positions are labeled in blue. The other atoms are labeled in black. The dihedral angles discussed in the text are numbered in the counterclockwise direction starting from ring A: 1: N_C, C4C, CHD, C1D; 2: C4C, CHD, C1D, N_D; 3: N_D, C4D, CHA, C1A; 4: C4D, CHA, C1A, N_A; 5: N_A, C4A, CHB, C1B; 6: C4A, CHB, C1B, N_B; 
(a) Neutral pH
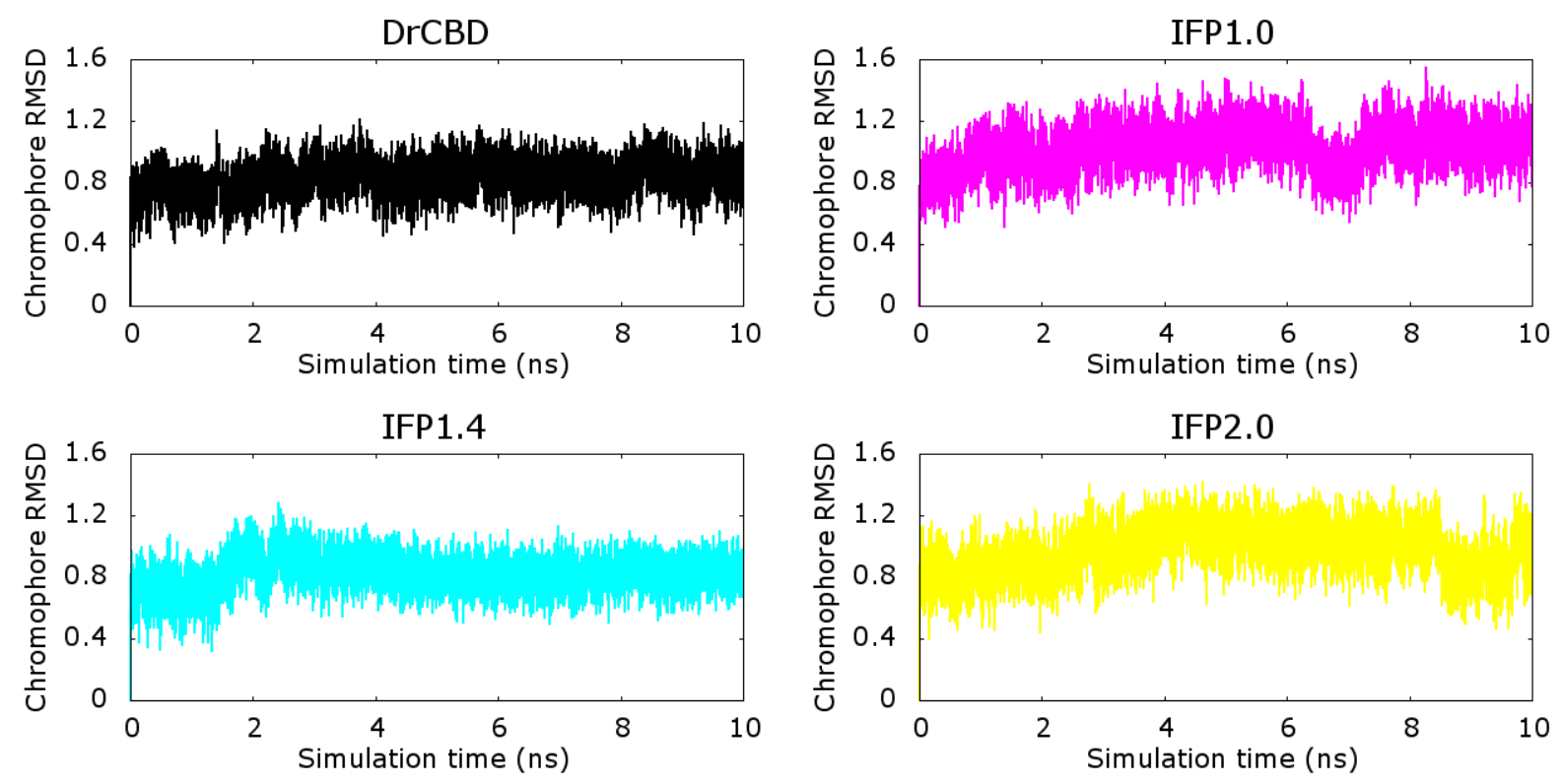

(b) Low $\mathrm{pH}$
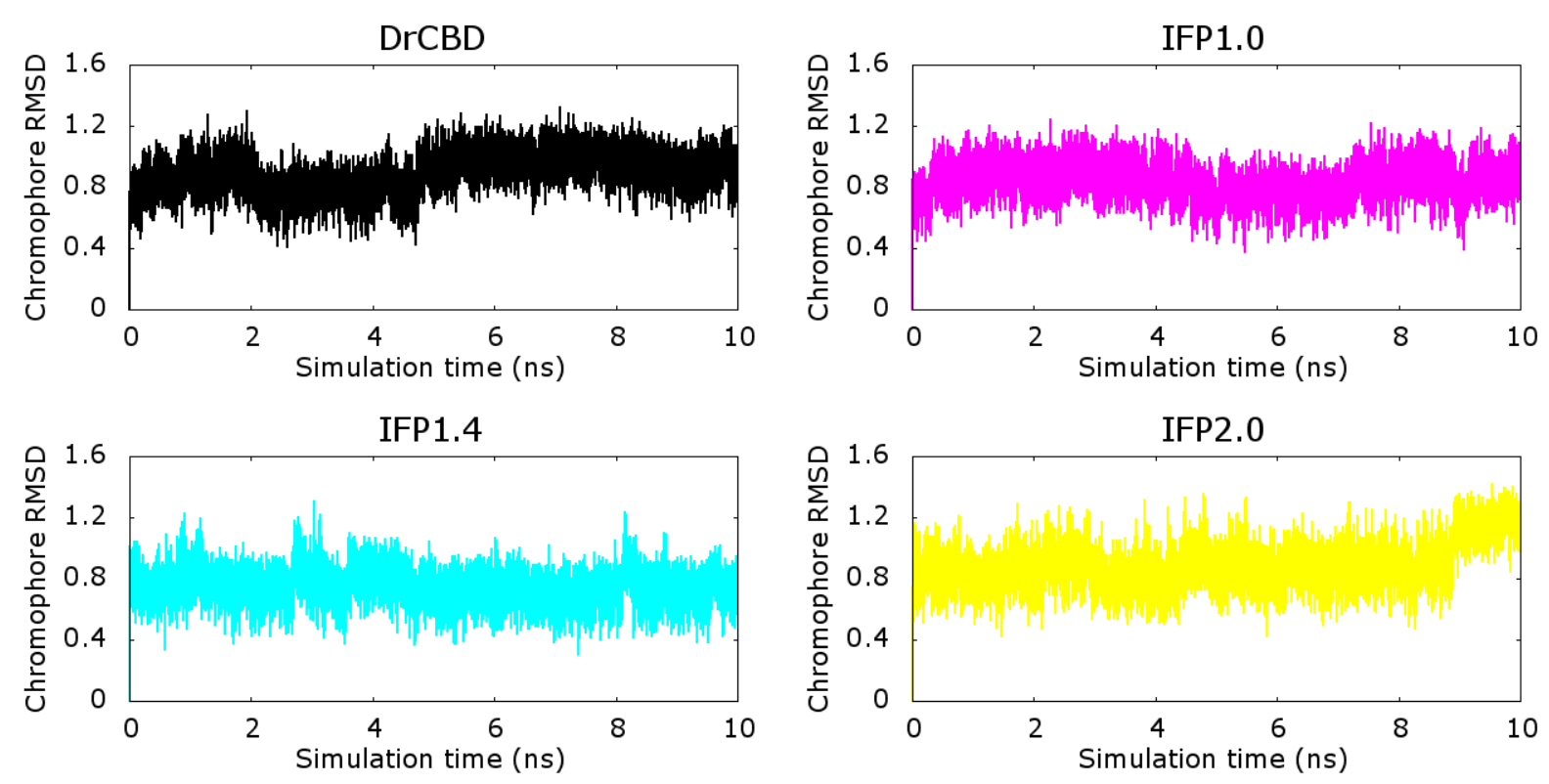

Figure S5: Time evolution of the root-mean-square deviations of the chromophore atoms in different proteins with respect to the final geometry from the heating stage. Two situations are shown: a) neutral $\mathrm{pH}$; and b) low $\mathrm{pH}$. 

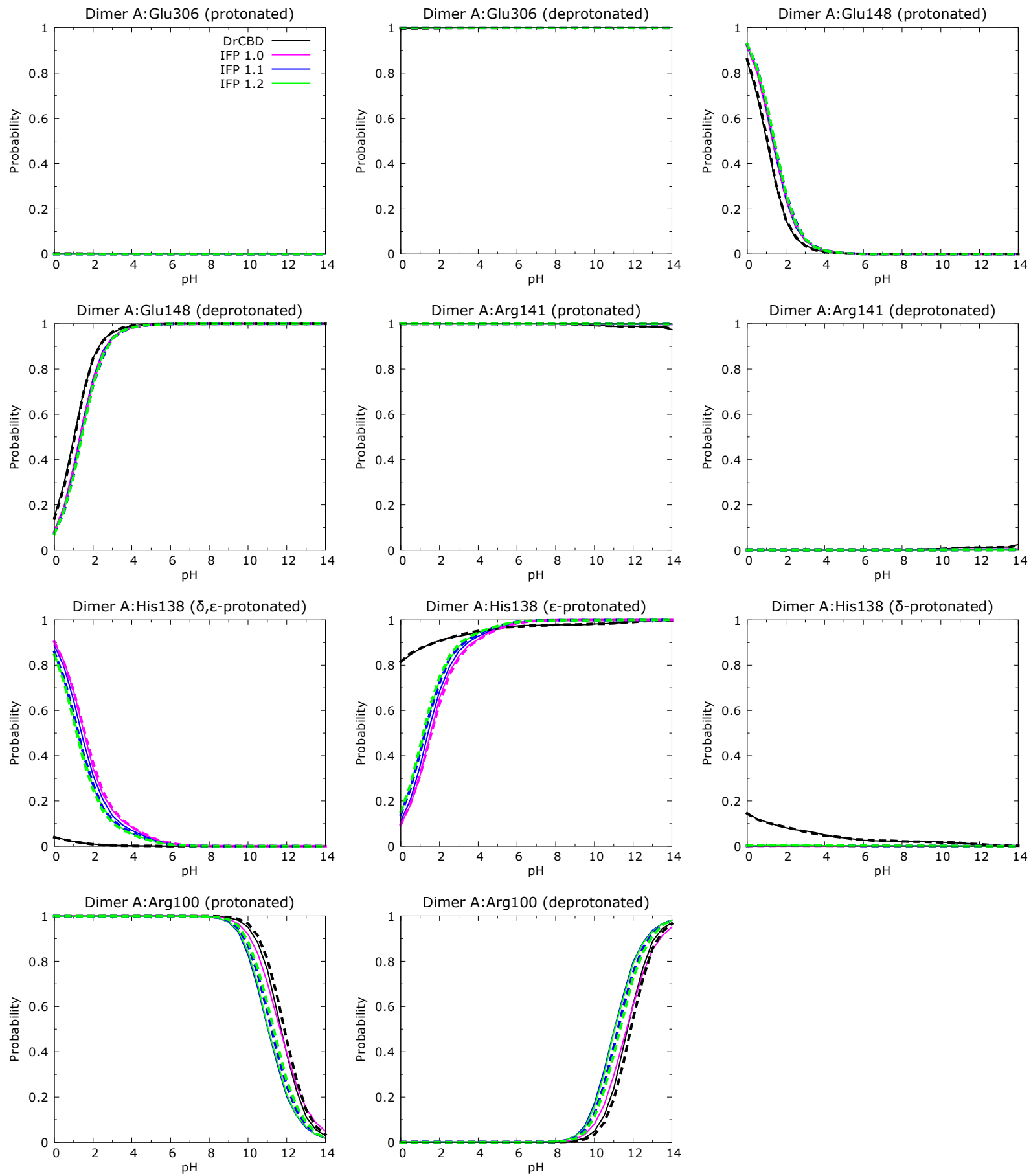

Figure S6: Titration curves of different protonation forms of titratable residues at the interface between the monomers (Arg100, His138, Arg141, Glu148, and Glu306). The calculations were performed on the structure of the complete dimer; only the curves for monomer A are shown. Solid and dashed lines represent the situations with the fully protonated and B-deprotonated chromophore, respectively. 

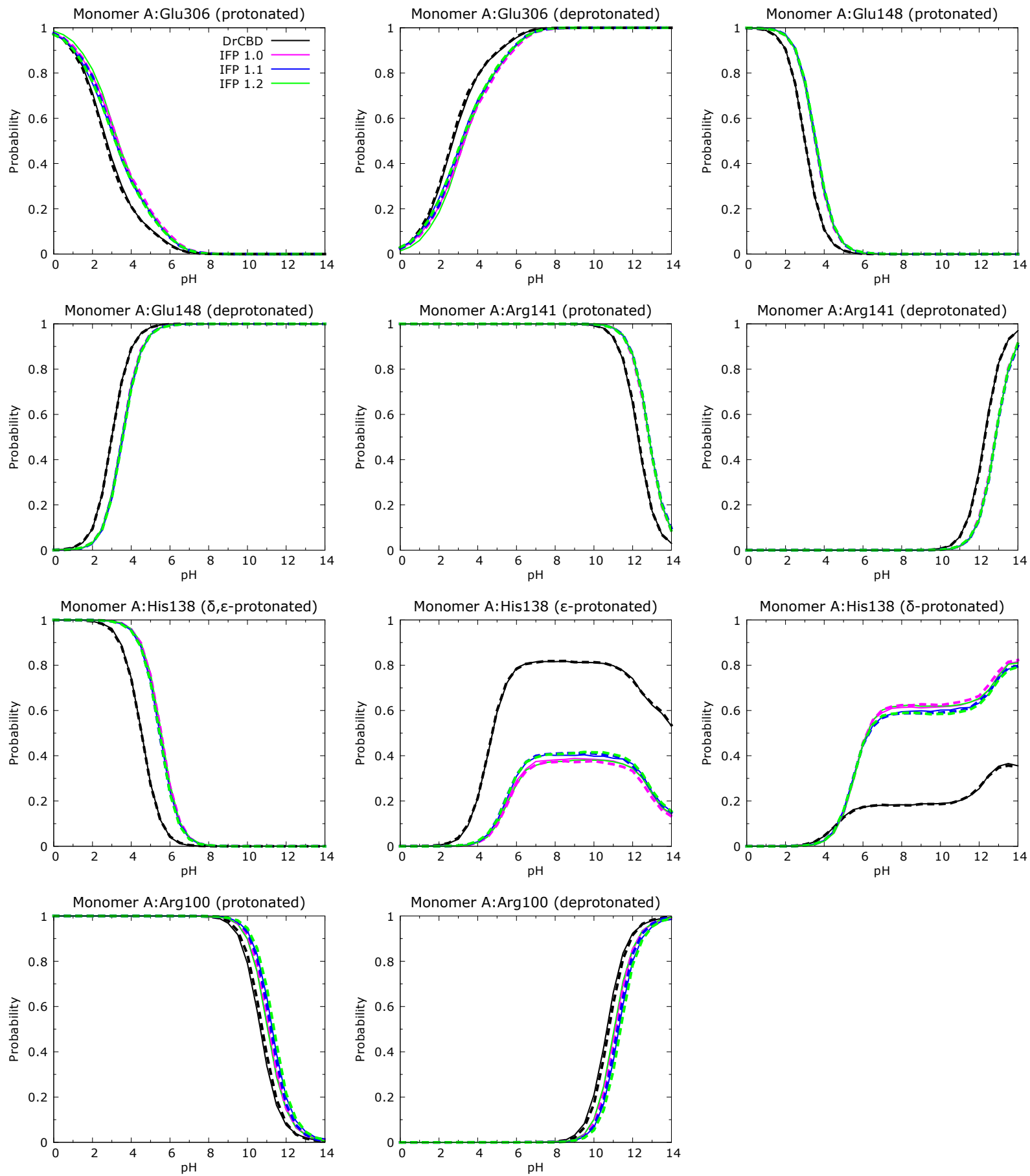

Figure S7: Titration curves of different protonation forms of titratable residues at the interface between the monomers (Arg100, His138, Arg141, Glu148, and Glu306). The calculations were performed on the structure of the isolated monomer A; monomer B has been removed from the model. Solid and dashed lines represent the situations with the fully protonated and B-deprotonated chromophore, respectively. 

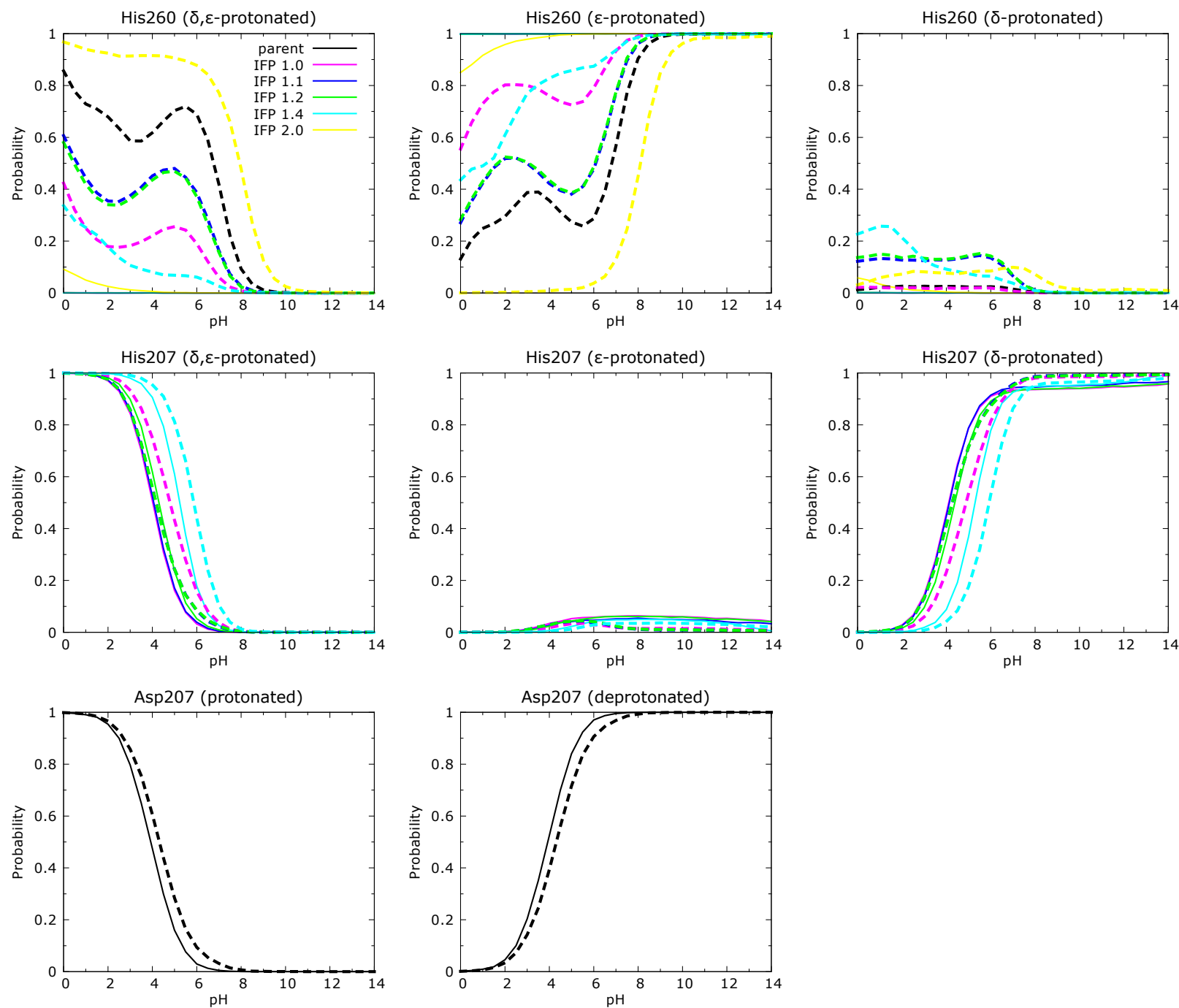

Figure S8: Probabilities of occurrence, calculated as a function of $\mathrm{pH}$, of different protonation forms of His260, Asp207 and His207. The plots of the fully deprotonated forms of the histidines were omitted for clarity, since their probabilities of occurrence were calculated to be always zero. Solid and dashed lines represent the situations with the chromophore fixed in its fully protonated and B-deprotonated form, respectively. If the chromophore is fully protonated, His260 remains $\epsilon$-protonated. Otherwise, His260 shows an irregular protonation behavior, where two protonation forms dominate, $\epsilon$ - or fully protonated, depending on the $\mathrm{pH}$ and the particular protein. Asp207 displays a typical protonation behavior. His207 has its midpoint $\mathrm{p} K_{\mathrm{a}}$ in the range of $4<\mathrm{pH}<6$, where the fluorescence is known to rapidly increase. The probability curves for Asp207 and His207 show only small displacements depending on the protonation state of the chromophore. The probability curves of IFP 1.1 and IFP 1.2 align closely, because these mutant proteins differ by only a single mutation in a region remote from the chromophore. 

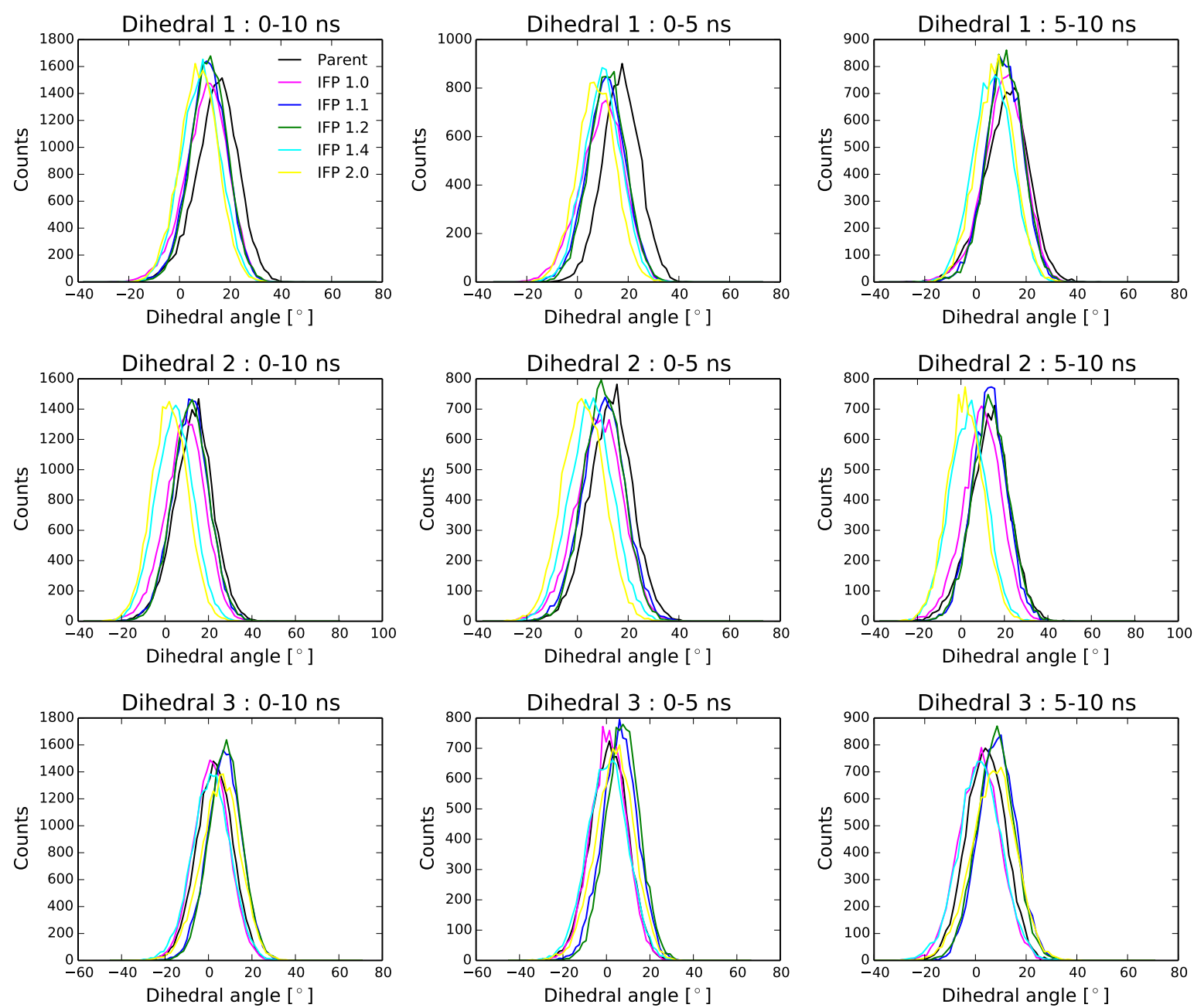

Figure S9: Statistical distributions of dihedral angles 1-3 of the chromophore for all proteins. The simulations were performed at neutral $\mathrm{pH}$ and with the chromophore in its fully protonated form. Three distributions are shown for each dihedral, calculated from the full (0-10 ns) simulation, and from the first (0-5 ns) and second (5-10 ns) halves. See Fig. 3 in the paper for the definitions of the dihedrals. 

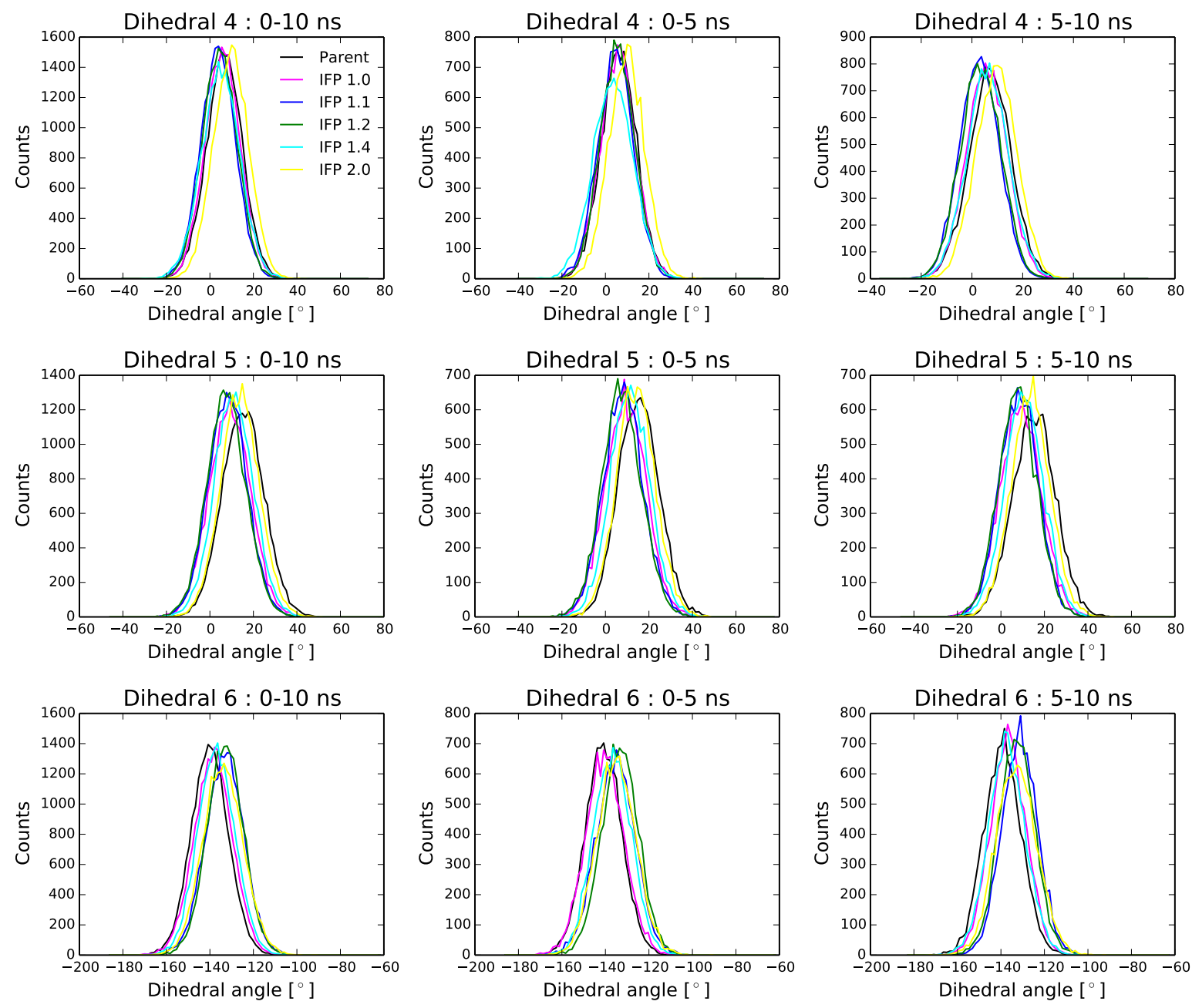

Figure S10: Statistical distributions of dihedral angles 4-6 of the chromophore for all proteins. The simulations were performed at neutral $\mathrm{pH}$ and with the chromophore in its fully protonated form. Three distributions are shown for each dihedral, calculated from the full (0-10 ns) simulation, and from the first (0-5 ns) and second (5-10 ns) halves. See Fig. 3 in the paper for the definitions of the dihedrals. 

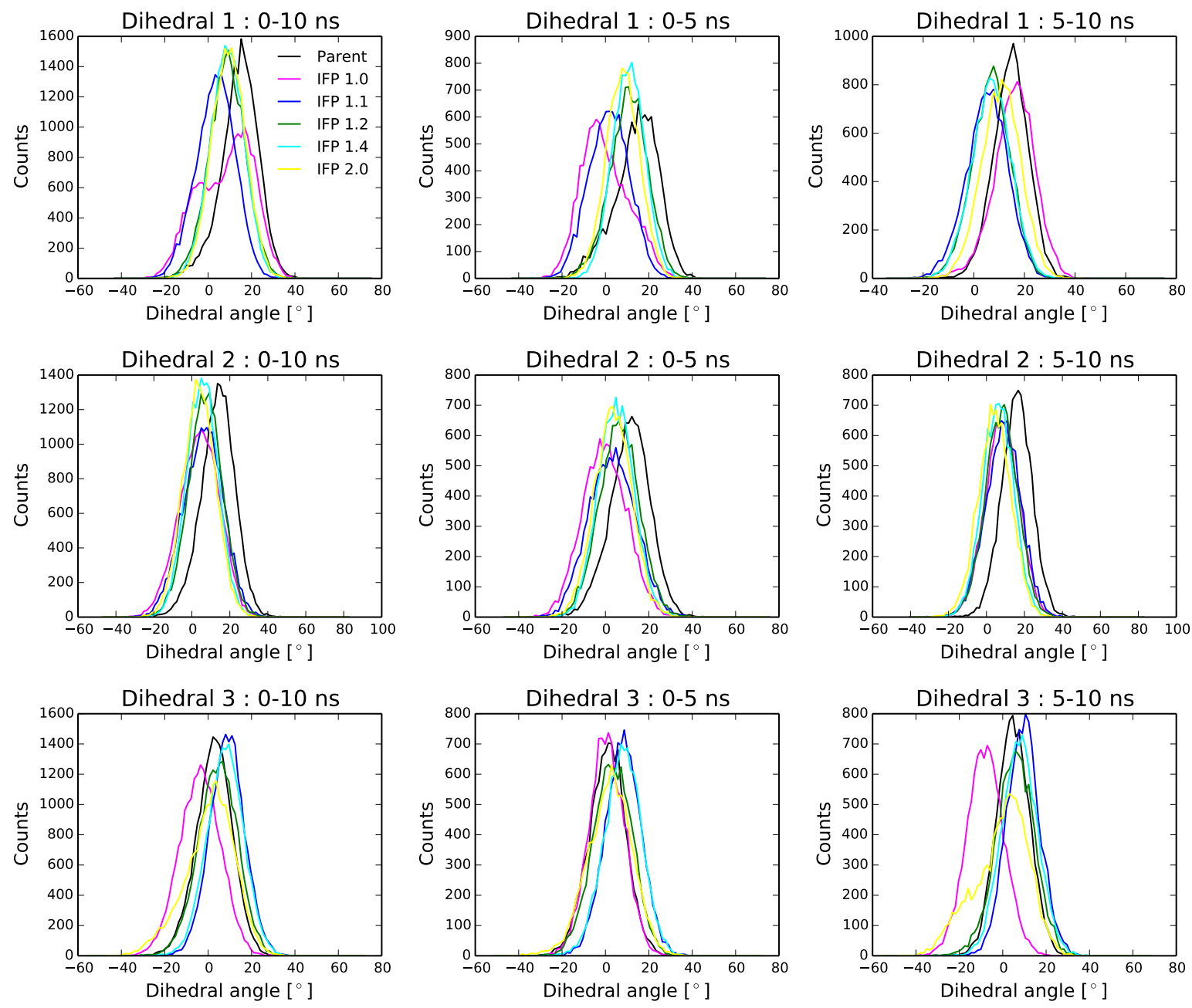

Figure S11: Statistical distributions of dihedral angles 1-3 of the chromophore for all proteins. The simulations were performed at low $\mathrm{pH}$ and with the chromophore in its fully protonated form. Three distributions are shown for each dihedral, calculated from the full (0-10 ns) simulation, and from the first (0-5 ns) and second (5-10 ns) halves. See Fig. 3 in the paper for the definitions of the dihedrals. 

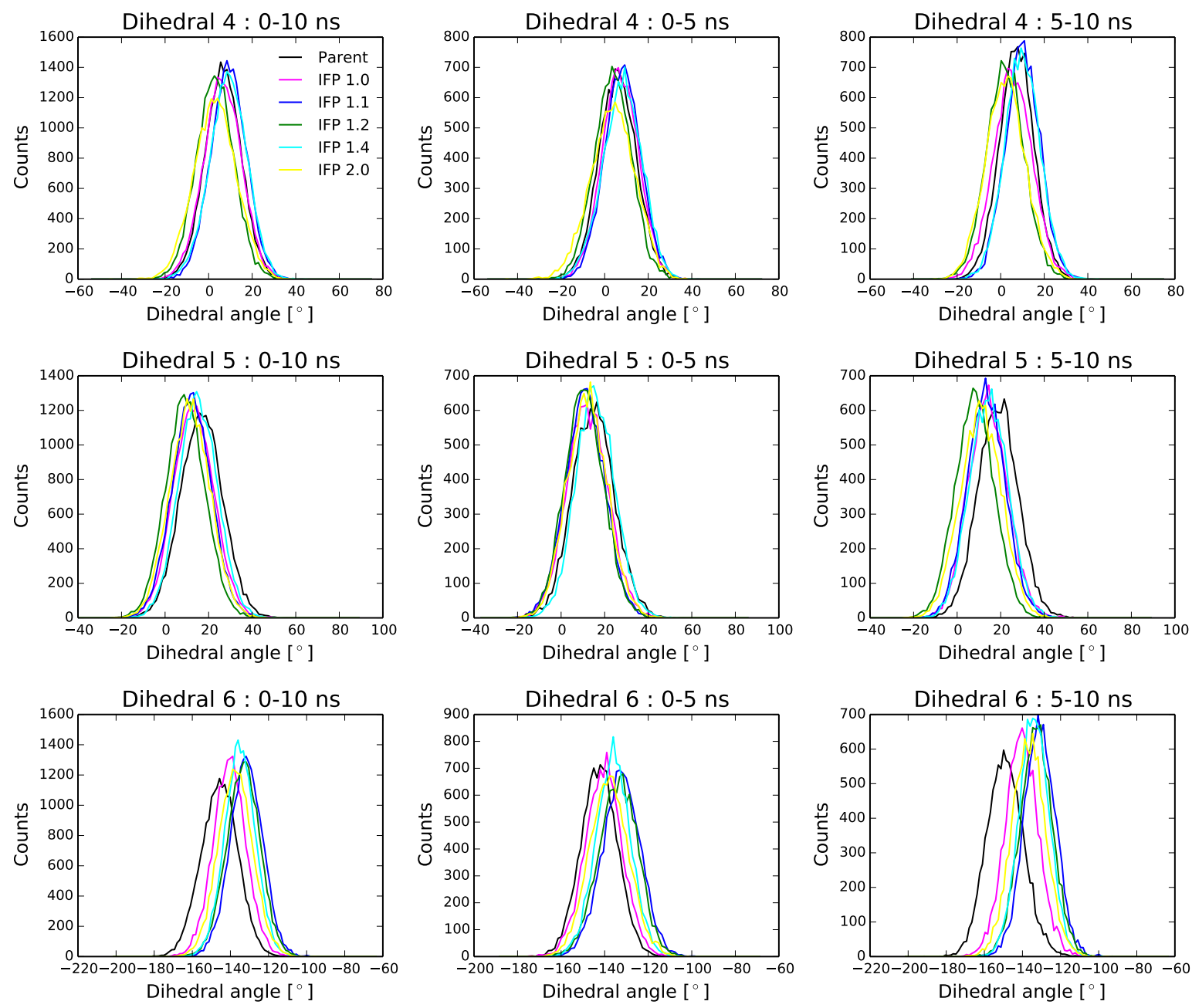

Figure S12: Statistical distributions of dihedral angles 4-6 of the chromophore for all proteins. The simulations were performed at low $\mathrm{pH}$ and with the chromophore in its fully protonated form. Three distributions are shown for each dihedral, calculated from the full (0-10 ns) simulation, and from the first (0-5 ns) and second (5-10 ns) halves. See Fig. 3 in the paper for the definitions of the dihedrals. 


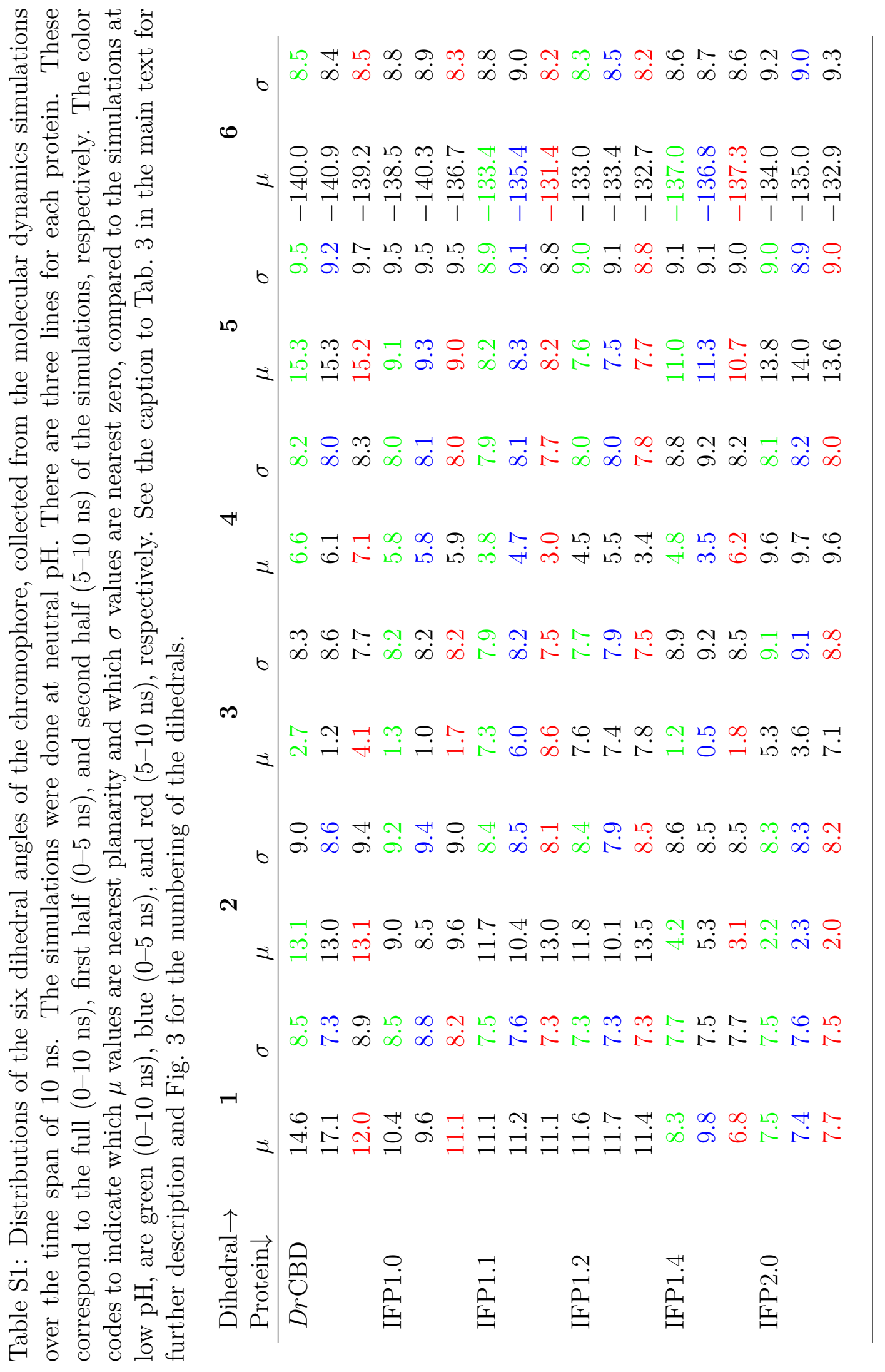




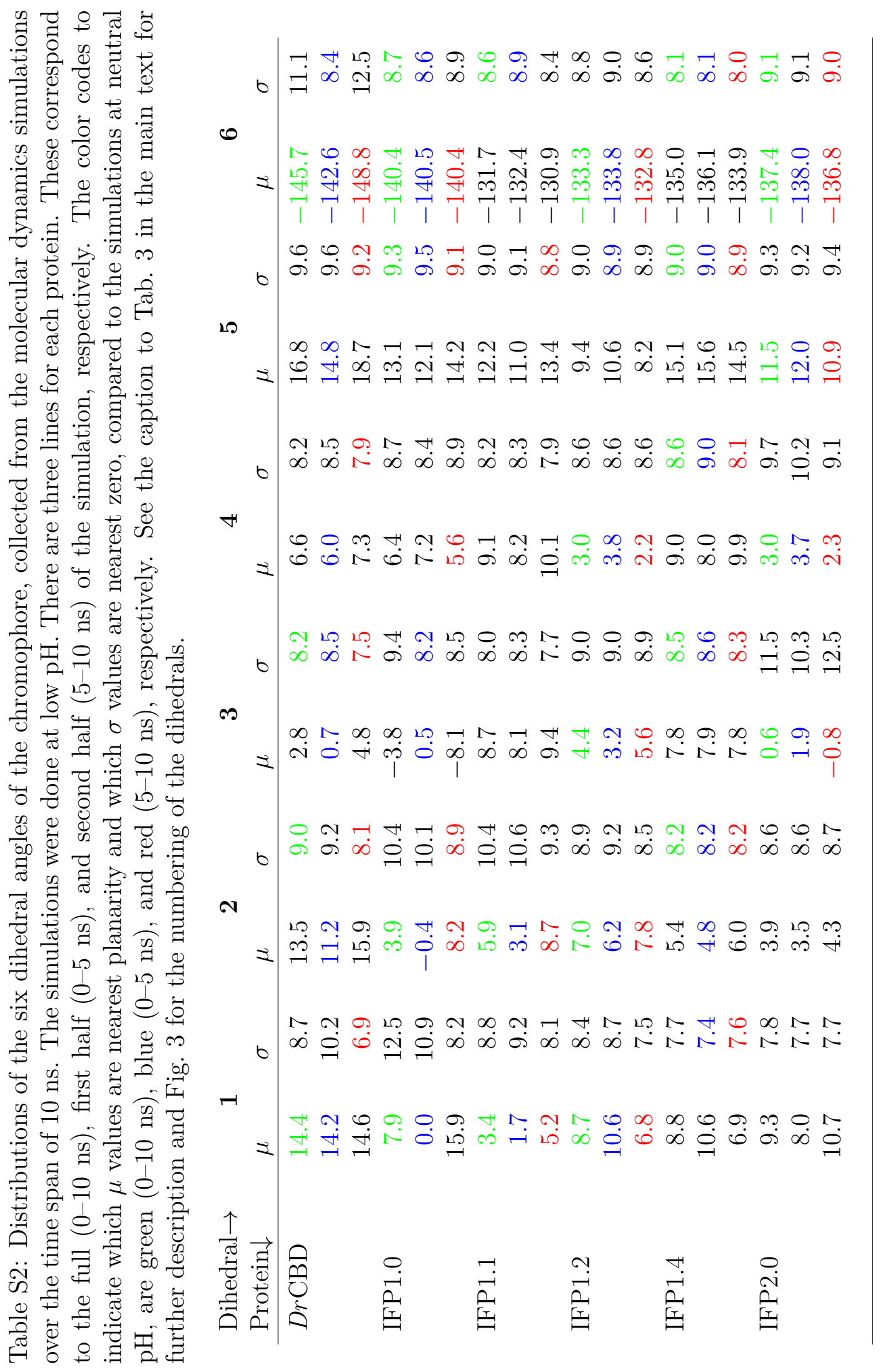




\section{S1 Statistical distribution of the important dihedral angles of the chromophore.}

In the present section, we analyze in detail the intrinsic dynamics of the protein-bound biliverdin in different IFPs by focussing on the six dihedral angles of the chromophore located between the pyrrole rings defined in Fig. 3.

In the main text, Fig. 4 and Tab. 3 show the plotted distributions and fitted normal distribution parameters, $\mu$ and $\sigma$, for each of the proteins calculated from the last 5 ns of the 10 ns molecular dynamics simulations. By contrast, data from the complete simulations, together with separate analyses of the first and second halves, are given in Figs. S9-S12 and Tabs. S1 and S2.

Initially we consider briefly the differences between the dihedral distributions from the first and second halves of the molecular dynamics simulations. Overall, a perusal of Figs. S9-S12 and Tabs. S1 and S2 indicates that the distributions between the two halves are consistent, and that any trends that are present, such as for dihedral angles $\mathbf{1}$ and 2 (see below), are maintained. The principle exception to this observation is for the simulation of IFP 1.0 at low pH. At the start of the simulation, dihedral angles $\mathbf{1}$ and $\mathbf{3}$ are close to planarity, but they undergo a concerted shift to non-planarity in the second half of the simulation, adopting means of 15.9 and $-8.1^{\circ}$, respectively.

In what follows we shall concentrate on the distributions from the last $5 \mathrm{~ns}$ of the molecular dynamics simulations, and we start with the simulations performed at neutral pH. As seen on Fig. 4a in the main text, the differences between the distributions for the two dihedral angles located between the chromophore rings $\mathrm{A}$ and $\mathrm{B}$, labeled $\mathbf{1}$ and $\mathbf{2}$, are quite pronounced. Ring $\mathrm{A}$ is adjacent to the covalent binding site of the chromophore to Cys24. In $\operatorname{Dr} \mathrm{CBD}$, dihedral 1 angle shows a mean value of $12.0^{\circ}$, indicating a noticeable distortion of planarity (see Tab. 3 for the comparison of the calculated statistical parameters of each dihedral in all proteins). In IFP1.0, which is only a weakly fluores- 
cent protein, dihedral 1 is only slightly shifted towards planarity by $1.0^{\circ}$ in comparison to the parent protein. In the most fluorescent proteins, the mean value of dihedral $\mathbf{1}$ is further reduced to $6.8^{\circ}$ in IFP1.4 and $7.7^{\circ}$ in IFP2.0, which indicates a dihedral about $40 \%$ more planar than in the parent protein. For the generated models of IFP1.1 and IFP1.2, the mean values were calculated to be $11.1^{\circ}$ and $11.4^{\circ}$, respectively. While the mean parameter of dihedral $\mathbf{1}$ is shifted depending on the studied protein, the simulations show only small decreases in the variance parameter. For example, the flexibility of the chromophore region involving dihedral 1 was calculated to be 8.9 and 7.5 for $\operatorname{DrCBD}$ and IFP2.0, respectively. Thus, the flexibility of the chromophore fragment involving dihedral 1 seems to be comparable in all proteins. As indicated in the main manuscript, the observed differences in the planarity can be related to the migration of water molecules in the vicinity of the chromophore.

Dihedral angle 2 displays the most significant differences in planarity, depending on the protein. The mean parameter for dihedral 2 was calculated to be $13.1^{\circ}$ in $\operatorname{DrCBD}$ and is already reduced to $9.6^{\circ}$ in IFP1.0. Dihedral 2 shows a significant improvement of planarity in IFP1.4 and to a greater extent in IFP2.0. Namely, the $\mu$ parameter was calculated to be as low as $3.1^{\circ}$ in IFP1.4 and 2.0 ${ }^{\circ}$ in IFP2.0. For IFP1.1 and IFP1.2, dihedral 2 has similar values to that of the parent protein $\left(\mu=13.0\right.$ and $13.5^{\circ}$, repectively). However, the models for these proteins were generated by substitution of the relevant residues in $\operatorname{DrCBD}$, since the corresponding crystal structures were not available. Hence, one has to allow for a wider margin of uncertainty when considering these two proteins. Similarly to dihedral $\mathbf{1}$, the rigidity of this dihedral is only slightly reduced during the transition from the parent protein $(D r C B D)$ to the other IFPs. The variance parameter was calculated to be $\sigma=9.4$ in $\operatorname{DrCBD}$ and changes to only $\sigma=8.2$ in IFP2.0.

Compared to dihedrals $\mathbf{1}$ and $\mathbf{2}$, the dynamics of the other four dihedrals show lesser dependence on the protein. Dihedral 3, which is part of the link between rings B and C, has a mean value of $4.1^{\circ}$ in $\operatorname{DrCBD}$. The value is reduced to $1.7^{\circ}$ in IFP1.0 and $1.8^{\circ}$ in 
IFP1.4, but eventually becomes $7.1^{\circ}$ in IFP2.0. For the models of the intermediate proteins, dihedral 3 was calculated to be even less planar than in the other proteins ( $\mu=8.6^{\circ}$ and $\mu=7.8^{\circ}$ for IFP1.1 and IFP1.2, respectively). Dihedral 4 shows a rather irregular dynamics and its out-of-plane character generally increases on going from $\operatorname{DrCBD}$ to IFP2.0. A similar behavior is seen in the case of dihedral $\mathbf{5}$, where there is a considerable tilt between rings $\mathrm{C}$ and $\mathrm{D}$. The $\mu$ parameter of dihedral $\mathbf{5}$ was calculated to be $15.2^{\circ}$ in $\operatorname{DrCBD}$ and $13.6^{\circ}$ in IFP2.0, despite some improvement of planarity in the intermediate proteins. Finally, dihedral 6 shows a similar behavior to dihedrals 4 and $\mathbf{5}$ as its planarity decreases from $\mu=-139.2^{\circ}$ in the parent protein to $\mu=-132.9^{\circ}$ in IFP2.0, whereas its rigidity again does not change much. A somewhat similar trend in the dynamics of dihedral 6 has been reported in the earlier study on phytochromes, where a greater tilt was observed for the mutant protein. ${ }^{4}$

From the simulations performed at neutral $\mathrm{pH}$, we note that the flexibility of all dihedrals remains similar regardless of the protein. Namely, the $\sigma$ parameter indicating the flexibility of the particular fragment of the chromophore was always calculated to be within the range of $\sigma=7.3$ to $\sigma=9.7$. Fragments of the chromophore involving dihedrals 3 to 6 are located closer to the center of the protein than the fragments involving dihedrals 1 and 2 .

We next discuss the simulations performed at low $\mathrm{pH}$. Protonation of different groups in the protein may disfavor the planar geometry of the chromophore, leading to the eventual loss of fluorescence. Similarly to the situation at neutral $\mathrm{pH}$, dihedral $\mathbf{1}$ is significantly distorted in $\operatorname{Dr} \mathrm{CBD}\left(\mu=14.6^{\circ}\right)$. On going from the parent protein to the fluorescent mutants, the improvement of planarity is not as pronounced as at neutral $\mathrm{pH}$. The two most fluorescent proteins show dihedral 1 more tilted $\left(\mu=6.9^{\circ}\right.$ for IFP1.4 and $\mu=10.7^{\circ}$ for IFP2.0) than in the intermediate proteins (for example, $\mu$ was calculated to be $5.2^{\circ}$ for IFP1.1).

Dihedral 2 has a considerable tilt of $\mu=15.9^{\circ}$ in $\operatorname{DrCBD}$ but this reduces markedly 
to $\mu=8.2^{\circ}$ in IFP1.0. In contrast to the situation at neutral $\mathrm{pH}$, the mean values of dihedral 2 for IFP1.1 and IFP1.2 are similar to those of IFP1.0, and were calculated to be $8.7^{\circ}$ and $7.8^{\circ}$, respectively. In the most fluorescent proteins, the tilt is further slightly reduced to $6.0^{\circ}$ for IFP1.4 and $4.3^{\circ}$ in IFP2.0. The orientation of rings A and B of the chromophore seems more planar at neutral $\mathrm{pH}$ if one considers the parent protein and the most fluorescent proteins. However, the trend is reversed for the intermediate proteins, in which dihedral $\mathbf{2}$ is less tilted at low $\mathrm{pH}$. For both dihedrals, there do not appear to be significant differences in flexibility between low and high $\mathrm{pH}$.

At lower $\mathrm{pH}$, the dynamic behavior of the remaining four dihedrals is again less systematic, reinforcing the idea that the planarity of dihedrals $\mathbf{1}$ and $\mathbf{2}$ is most critical in improving the fluorescence of the chromophore. The flexibility of dihedral 3 varies to some extent depending on the protein, but does not show the same clear trend that is visible for dihedrals $\mathbf{1}$ and $\mathbf{2}$. Interestingly, the overall flexibility of dihedral $\mathbf{3}$ is increased in the situation at lower $\mathrm{pH}$, with the exception of $\operatorname{DrCBD}$ and IFP1.4, where the difference between neutral and lower $\mathrm{pH}$ is only slight. For example, the calculated variance parameter for IFP2.0 is $\sigma=8.8$ at neutral $\mathrm{pH}$ and $\sigma=12.5$ at low $\mathrm{pH}$. The trend for dihedral 4 is somewhat mixed with it being more tilted at low $\mathrm{pH}$ for the parent protein, and for IFP1.1 and IFP1.4, and also more flexible in four out of six cases. Dihedral $\mathbf{5}$ shows a rather significant displacement from planarity, which is related to the orientation of ring $\mathrm{D}$ of the chromophore. The tilt is also greater now than in the situation at neutral $\mathrm{pH}$, with the exception of IFP2.0. For $\operatorname{DrCBD}$, the dihedral's mean was calculated to be $15.2^{\circ}$ at neutral $\mathrm{pH}$ and $18.7^{\circ}$ at low $\mathrm{pH}$. For IFP2.0, this parameter is 13.6 and 10.9 for neutral and low $\mathrm{pH}$, respectively. In both acidities, there is a visible trend towards planarity for dihedral $\mathbf{5}$ on going from the parent protein towards more fluorescent proteins. Finally, the dynamics of dihedral 6 is reversed compared to the case at $\mathrm{pH}=7$. With the exception of IFP1.1 and IFP1.4, dihedral 6 at lower $\mathrm{pH}$ was predicted to be closer to its planar conformation defined as $-180^{\circ}$. 
In summary, the performed simulations suggest that there is a connection between the introduced mutations and the dynamics of the chromophore. Dihedral angles $\mathbf{1}$ and $\mathbf{2}$ are shown to be generally the most distorted. Nevertheless, because of the additional mutations, the two dihedrals can be gradually planarized and restrained to some extent, especially in IFP1.4 and IFP2.0. Similar but less pronounced trends are visible for the other dihedrals. The mutations increasingly enforce the planarity of the chromophore and reduce motion around the conjugated bonds important for fluorescence. We note that not all mutations are beneficial for the improved planarity and rigidity of the chromophore. Some of the effects observed for IFP1.1 and IFP1.2 may result from the fact that the models representing these proteins were generated by modifying the structure of the parent protein and thus may not be fully reliable. Although the dynamics of the chromophore are somewhat altered after changing the $\mathrm{pH}$ from neutral to low, it is difficult to definitely pinpoint the factors responsible for the reported loss of fluorescence. Concerning the planarity of the chromophore, at low $\mathrm{pH}$ some of the dihedrals become more distorted compared to the situation at neutral $\mathrm{pH}$, most importantly $\mathbf{1}$ and $\mathbf{2}$. Interestingly, in four out of the six cases the flexibility of the dihedrals is increased at low pH (Tab. 3), although the observable differences in comparison to the situation at neutral $\mathrm{pH}$ are rather small. The overall decrease of the chromophore's rigidity at low pH may probably lead to some reduction of fluorescence, but we are not convinced that this can explain the complete loss of the fluorescence properties, as seen from the measurements performed for IFP $1.4^{5}$ and the other proteins (Fig. S3). We propose that, in addition to the increased flexibility of the chromophore, as seen in our molecular dynamics simulations, another mechanism might be involved in the reduction of fluorescence at low $\mathrm{pH}$, for example quenching upon chromophore deprotonation or denaturation of the protein. 


\section{S2 Calculations of different protonation forms of bili- verdin in the gas phase.}

The key difficulty in the computational treatment of nonstandard titratable groups, such as the biliverdin chromophore, is that the $\mathrm{p} K_{\mathrm{a}}$ values of these groups in aqueous solution are often not known. For a known $\mathrm{p} K_{\mathrm{a}}$ in aqueous solution, i.e. $\mathrm{p} K_{\mathrm{a}}^{\mathrm{aq}}$, one can calculate its shift while moving the protonatable group from the solvent phase to the protein. The calculation is usually done by using the Poisson-Boltzmann electrostatic model, like the one employed in the present study. ${ }^{6}$ These $\mathrm{p} K_{\mathrm{a}}^{\mathrm{aq}}$ values, if not available from experiment, can be estimated computationally by using a variety of methods. ${ }^{7,8}$ However, reliable calculations of $\mathrm{p} K_{\mathrm{a}}^{\mathrm{aq}}$ values represent a rather difficult task. In the present study, we took a different approach, in which we simply fixed the protonation state of the protein-bound biliverdin to its either fully protonated or B-deprotonated form during the electrostatic calculations.

The choice of the B-deprotonated form was based on the comparison of the vacuum energies of all deprotonated forms of the chromophore, calculated using the BP density functional theory method and the $\operatorname{TZV}(2 \mathrm{~d})$ basis sets (TZV $(\mathrm{p})$ for hydrogens). The Bdeprotonated form was always the lowest in energy and the A-, C- and D-deprotonated forms were higher in energy by, respectively, 1.8, 5.9 and $29.1 \mathrm{kcal} / \mathrm{mol}$. Thus, ring B was assumed to be the most likely deprotonation site. From our vacuum calculations, we note that the conformation of the isolated chromophore is dependent on the protonation of its pyrrole rings (Fig. S13). The A-, B- and C-deprotonated forms display a relatively planar geometry compared to the D- deprotonated or fully protonated forms. Removal of a

pyrrole proton from ring $\mathrm{A}, \mathrm{B}$ or $\mathrm{C}$ reduces the mutual repulsion between the rings, which is due to the confined inner protons. It also introduces a hydrogen-bond acceptor, to which intramolecular hydrogen bonds can be formed, further stabilizing the planar structure of the chromophore. For example, removal of hydrogen B enables intramolecular hydrogen 
bonds between the pyrrole nitrogen of ring $\mathrm{B}$ and the hydrogens from rings $\mathrm{A}$ and $\mathrm{C}$. By contrast, the geometries of the D-deprotonated and fully protonated forms show three positively charged hydrogens on rings $\mathrm{A}, \mathrm{B}$ and $\mathrm{C}$ in rather close contact. Thus, in the optimized geometry of the fully protonated chromophore, the closest distance, of $2.2 \AA$ is between the A and B pyrrole hydrogens, where the distances between hydrogens A-C and B-C are $2.5 \AA$ and $2.3 \AA$, respectively. Since fluorescence is due to the conjugated system of $\pi$-electrons, the chromophore should ideally have a planar and rigid structure to maximize its fluorescent properties. Therefore, it is conceivable that the B-deprotonated form of the chromophore should be more fluorescent than the fully protonated form. Indeed, the fluorescence of IFPs diminishes at low pH (Fig. S3), at which we presume the chromophore is fully protonated. Note that we excluded from our considerations the doubly, triply and fully deprotonated forms of the chromophore since they are energetically unfavorable and therefore unlikely to occur under biological conditions. 


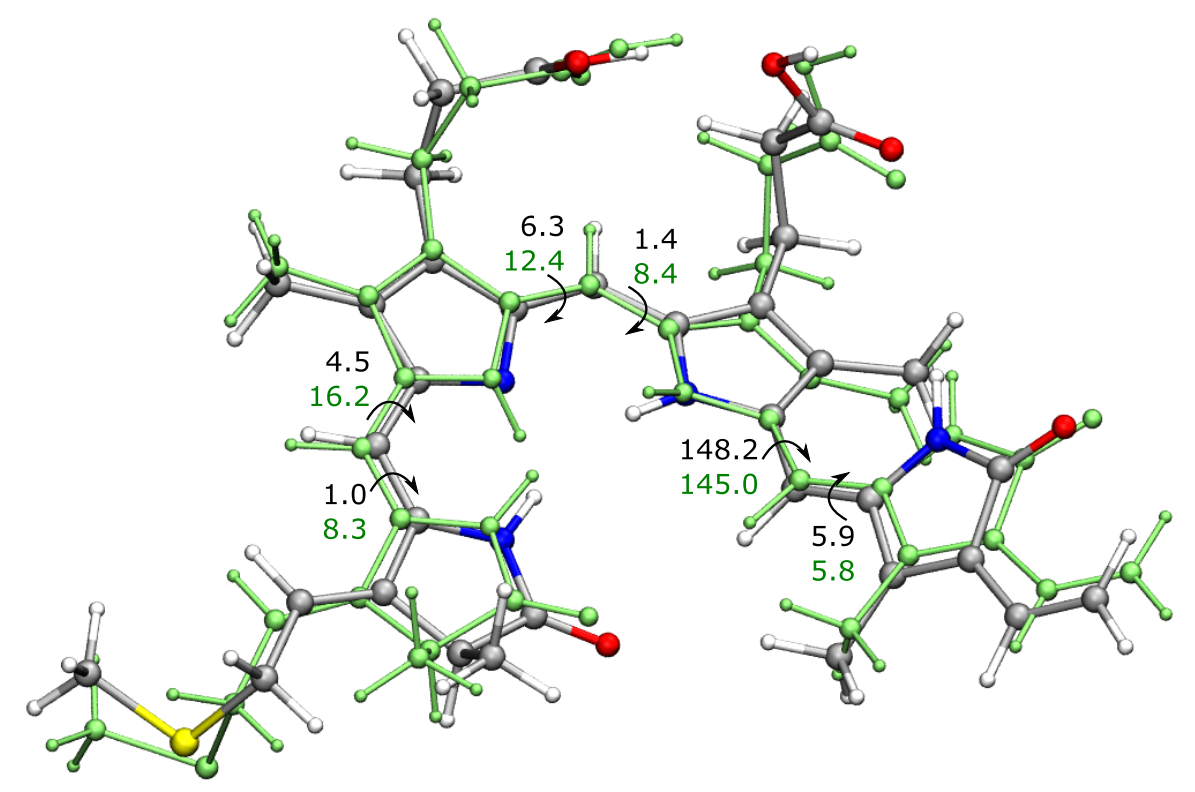

Figure S13: Superposition of the geometries of the fully protonated (shown in green) and B-deprotonated (shown in colors) forms of the free chromophore optimized at the $\mathrm{BP} / \mathrm{TZV}(\mathrm{p}) / \mathrm{TZV}(2 \mathrm{~d})$ level. Cysteine linker was modeled during the optimizations as a thiomethyl group. Carboxylic groups at rings $\mathrm{B}$ and $\mathrm{C}$ were neutralized by adding protons. Arrows indicate central bonds of the six important dihedral angles that define the planarity of the chromophore. Black and green labels indicate the values of the dihedrals for the B-deprotonated and fully protonated forms, respectively. The pyrrole rings $\mathrm{A}-\mathrm{B}-\mathrm{C}$ in the fully protonated form show an out-of-plane geometry because of the repulsion of the inner protons. The inclusion of the pyrrole water in the vacuum models does not change the overall picture. 


\section{S3 Derivation of parameters for the deprotonated chromophore.}

We refer to the biliverdin chromophore deprotonated at the B pyrrole ring simply as the B-deprotonated chromophore. The missing molecular mechanics parameters for the B-

deprotonated chromophore were derived starting from the available parameters of the fully protonated chromophore..$^{9,10}$ All quantum chemical calculations were done in ORCA $^{11}$ using the BP density functional theory method and the TZV(p) and TZV $(2 \mathrm{~d})$ basis sets for hydrogens and heavy atoms, respectively. In the first step, we prepared geometries of the isolated chromophore in its five protonation forms, namely the fully protonated form and the A-, B-, C-, and D-deprotonated form. The fully protonated form had a total charge of +1 and the other forms were neutral. The geometries of all forms were subsequently optimized in vacuum. Frequency analyses were performed on top of the optimized geometries of each form to ensure that the geometries were in their energy minima. In further calculations, only the fully protonated and the B-deprotonated forms were considered. The atomic charges for the isolated chromophore, both in its fully protonated and B-deprotonated form, were calculated using the CHELPG method. ${ }^{12}$ Differences in the CHELPG charges were calculated between the corresponding atoms of the two forms. These differences were subsequently added to the existing MM-charges of the fully protonated form to obtain the MM-charges charges for the B-deprotonated form. The missing force field parameters for the four dihedral angles between rings $\mathrm{A}, \mathrm{B}$ and $\mathrm{C}$ were derived following a two-step procedure. First, the complete chromophore was truncated to two separate molecular fragments, one comprising the rings $\mathrm{A}$ and $\mathrm{B}$, and the other one comprising the rings $\mathrm{B}$ and $\mathrm{C}$. The carboxylic groups at rings $\mathrm{B}$ and $\mathrm{C}$ were removed from the fragments to prevent possible sterical clashes during the consecutive scans. Points of truncation were saturated with hydrogen atoms. A relaxed potential energy surface scan was performed in steps of $5^{\circ}$ along the central bond of each of the four dihedrals. 
The scans were done both for the fully protonated form and the B-deprotonated form of the chromophore, using both the QC- and MM-potentials. The QC- and MM-scans were done in ORCA and pDynamo, respectively. Second, the dihedral parameters for the B-deprotonated form were manually tuned and the MM-scans were redone as long as a satisfactory fitting of the MM- and QC-generated energy profiles was achieved. The obtained fits for the B-deprotonated form show good agreement between the QC-profiles and MM-profiles (see Fig. S14). 

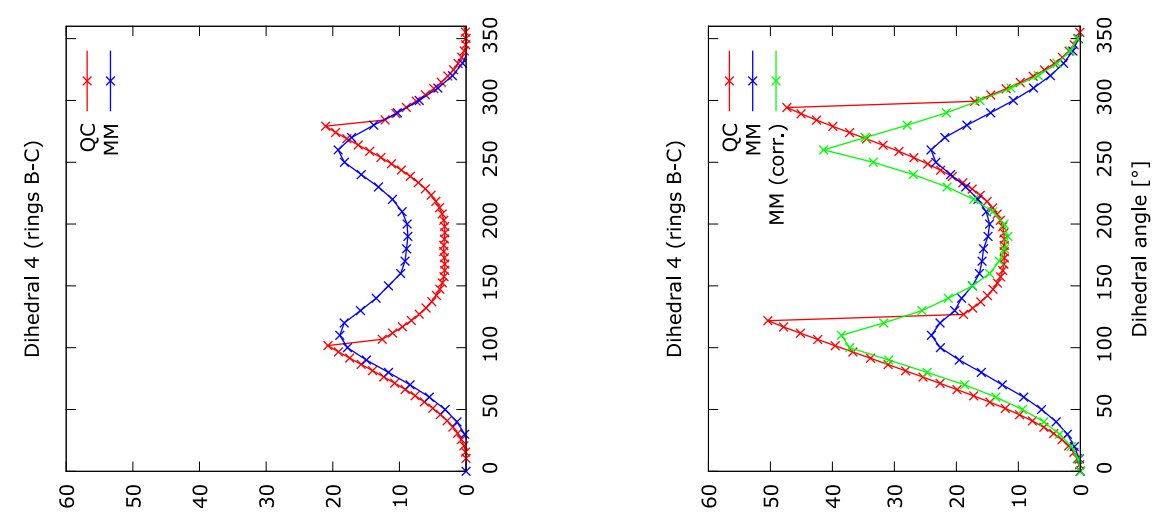

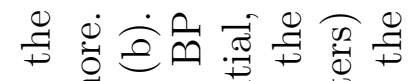

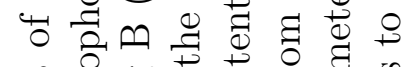

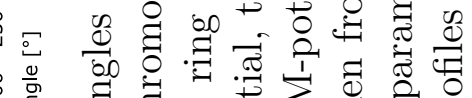

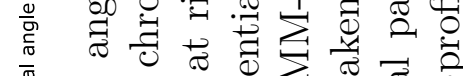

要

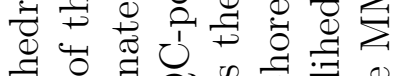
I)

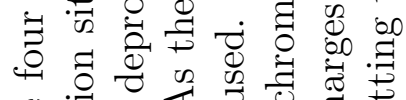

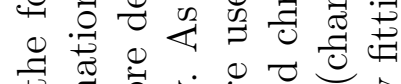
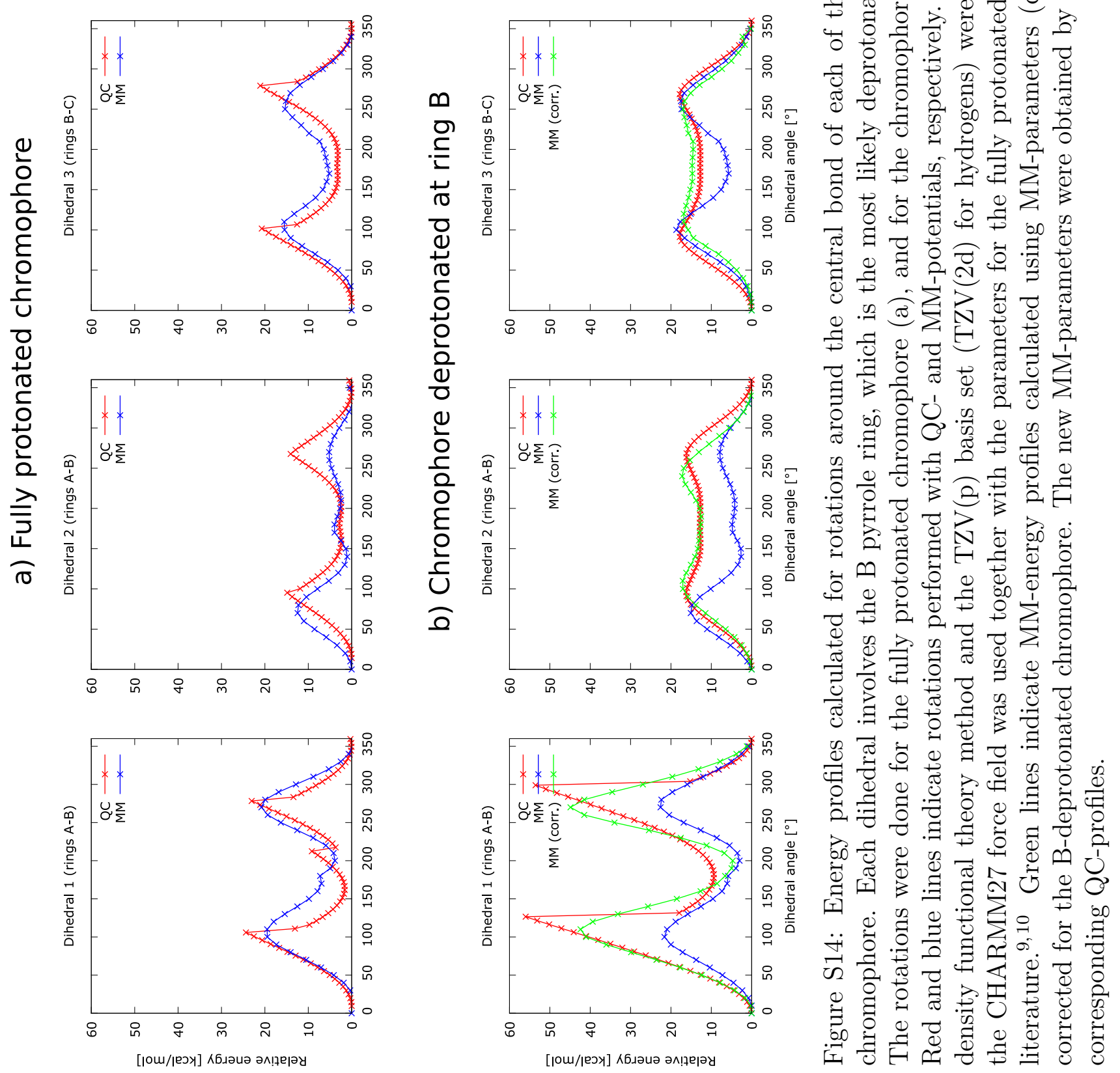
Figure S15: Topology file for the CHARMM force field to describe the biliverdin chromophore deprotonated at pyrrole ring $\mathrm{B}$, based on the previous topology of the fully protonated chromophore. ${ }^{9,10}$

\begin{tabular}{|c|c|c|c|}
\hline 31 & 1 & & \\
\hline MASS & 201 & CPY1 & 12.011 \\
\hline MASS & 202 & CPY2 & 12.011 \\
\hline MASS & 203 & СРY3 & 12.011 \\
\hline MASS & 204 & CPY4 & 12.011 \\
\hline MASS & 205 & CPY5 & 12.011 \\
\hline MASS & 206 & CPY6 & 12.011 \\
\hline MASS & 207 & $\mathrm{SE}$ & 32.060 \\
\hline
\end{tabular}

\begin{tabular}{|c|c|c|c|}
\hline \multicolumn{2}{|c|}{ RESI BLB } & \multicolumn{2}{|c|}{-2.00} \\
\hline GROUP & & ! methine & bridge \\
\hline ATOM & $\mathrm{CAC}$ & CPM & -0.034 \\
\hline ATOM & HAC & HA & 0.110 \\
\hline GROUP & & ! RING A & \\
\hline ATOM & $\mathrm{C} 1 \mathrm{C}$ & $\mathrm{C}$ & 0.267 \\
\hline ATOM & $\mathrm{H} 2 \mathrm{C}$ & $\mathrm{HA}$ & 0.045 \\
\hline ATOM & N_C & NR1 & -0.381 \\
\hline ATOM & $\mathrm{H}_{-} \mathrm{C}$ & $\mathrm{H}$ & 0.266 \\
\hline ATOM & $\mathrm{C} 4 \mathrm{C}$ & $\mathrm{CA}$ & 0.166 \\
\hline ATOM & $\mathrm{C} 3 \mathrm{C}$ & CPY1 & -0.140 \\
\hline ATOM & $\mathrm{C} 2 \mathrm{C}$ & CT1 & 0.333 \\
\hline ATOM & O_C & 0 & -0.505 \\
\hline \multicolumn{4}{|l|}{ GROUP } \\
\hline ATOM & CHD & CPY3 & -0.441 \\
\hline ATOM & HHD & $\mathrm{HA}$ & 0.185 \\
\hline GROUP & \multicolumn{3}{|c|}{ ! RING B } \\
\hline ATOM & C1D & $\mathrm{CPA}$ & 0.448 \\
\hline $\begin{array}{l}\text { ATOM } \\
!\end{array}$ & N_D & NR1 & -0.705 \\
\hline ATOM & C4D & $\mathrm{CPA}$ & 0.465 \\
\hline ATOM & C3D & $\mathrm{CPB}$ & -0.207 \\
\hline ATOM & $\mathrm{C} 2 \mathrm{D}$ & $\mathrm{CPB}$ & -0.002 \\
\hline GROUP & & & \\
\hline ATOM & CHA & CPM & -0.086 \\
\hline
\end{tabular}




\begin{tabular}{|c|c|c|c|}
\hline ATOM & HHA & HA & 0.304 \\
\hline GROUP & & ! RING C & \\
\hline ATOM & $\mathrm{C} 1 \mathrm{~A}$ & CPA & 0.021 \\
\hline ATOM & N_A & NR1 & -0.499 \\
\hline ATOM & H_A & $\mathrm{H}$ & 0.335 \\
\hline ATOM & $\mathrm{C} 2 \mathrm{~A}$ & CPY4 & -0.038 \\
\hline ATOM & C3A & CPB & -0.202 \\
\hline ATOM & $\mathrm{C} 4 \mathrm{~A}$ & CPA & 0.432 \\
\hline GROUP & & ! RING D & \\
\hline ATOM & C4B & $\mathrm{C}$ & 0.467 \\
\hline ATOM & N_B & NR1 & -0.579 \\
\hline ATOM & H_B & $\mathrm{H}$ & 0.429 \\
\hline ATOM & $\mathrm{C} 1 \mathrm{~B}$ & $\mathrm{CA}$ & 0.475 \\
\hline ATOM & $\mathrm{C} 2 \mathrm{~B}$ & CPY5 & -0.132 \\
\hline ATOM & C3B & CPY6 & -0.112 \\
\hline ATOM & O_B & 0 & -0.462 \\
\hline GROUP & & & \\
\hline ATOM & CHB & CPY2 & -0.491 \\
\hline ATOM & HHB & HA & 0.268 \\
\hline GROUP & & ! VINYL RIN & JG D \\
\hline ATOM & $\mathrm{CAB}$ & CE1 & -0.299 \\
\hline ATOM & HAB & HE1 & 0.292 \\
\hline ATOM & CBB & CE2 & -0.348 \\
\hline ATOM & HV1 & HE2 & 0.179 \\
\hline ATOM & HV2 & HE2 & 0.162 \\
\hline GROUP & & ! CH3 RING & A (Cys binding point) \\
\hline ATOM & $\mathrm{CBC}$ & CT2 & -0.107 \\
\hline ATOM & HL1 & $\mathrm{HA}$ & 0.087 \\
\hline ATOM & HL2 & HA & 0.051 \\
\hline GROUP & & ! CH3 RING & A (close to Cys) \\
\hline ATOM & $\mathrm{CMC}$ & CT3 & -0.173 \\
\hline ATOM & HE1 & $\mathrm{HA}$ & 0.040 \\
\hline ATOM & $\mathrm{HE} 2$ & HA & 0.042 \\
\hline ATOM & HE3 & HA & 0.032 \\
\hline GROUP & & ! CH3 RING & B \\
\hline ATOM & CMD & CT3 & -0.052 \\
\hline ATOM & HD1 & $\mathrm{HA}$ & -0.001 \\
\hline ATOM & HD2 & HA & 0.011 \\
\hline ATOM & HD3 & HA & 0.012 \\
\hline GROUP & & ! CH3 RING & $\mathrm{C}$ \\
\hline ATOM & CMA & СТ3 & -0.049 \\
\hline ATOM & HA 1 & HA & 0.028 \\
\hline ATOM & HA2 & HA & 0.030 \\
\hline ATOM & HA3 & HA & 0.038 \\
\hline GROUP & & ! CH3 RING & $\mathrm{D}$ \\
\hline ATOM & CMB & СT3 & -0.039 \\
\hline
\end{tabular}




\begin{tabular}{|c|c|c|c|c|c|c|c|c|}
\hline ATOM & HB1 & & $\mathrm{HA}$ & 0.045 & & & & \\
\hline ATOM & HB2 & & HA & 0.069 & & & & \\
\hline ATOM & HB3 & & HA & 0.036 & & & & \\
\hline GROUP & & $!$ & CH2_COO- & RING B & & Heme) & & \\
\hline ATOM & CBD & & CT2 & -0.28 & & & & \\
\hline АTOM & $\mathrm{HO} 3$ & & HA & 0.09 & & & & \\
\hline ATOM & $\mathrm{HO} 4$ & & HA & 0.09 & & & & \\
\hline ATOM & CGD & & $\mathrm{CC}$ & 0.62 & & & & \\
\hline ATOM & O2D & & $\mathrm{OC}$ & -0.76 & & & & \\
\hline ATOM & 01D & & $\mathrm{OC}$ & -0.76 & & & & \\
\hline GROUP & & ! & CH2 RING & B & & Heme) & & \\
\hline ATOM & CAD & & CT2 & -0.159 & & & & \\
\hline ATOM & $\mathrm{HOT}$ & & HA & 0.056 & & & & \\
\hline ATOM & HOE & & HA & 0.045 & & & & \\
\hline GROUP & & ! & CH2_COO- & RING C & & Heme) & & \\
\hline ATOM & CBA & & CT2 & -0.28 & & & & \\
\hline ATOM & $\mathrm{HO}$ & & $\mathrm{HA}$ & 0.09 & & & & \\
\hline ATOM & $\mathrm{HO} 2$ & & HA & 0.09 & & & & \\
\hline ATOM & $\mathrm{CG}$ & & $\mathrm{CC}$ & 0.62 & & & & \\
\hline ATOM & 021 & & $\mathrm{OC}$ & -0.76 & & & & \\
\hline ATOM & 011 & & $\mathrm{OC}$ & -0.76 & & & & \\
\hline GROUP & & ! & CH2 RING & $\mathrm{C}$ & & Heme) & & \\
\hline ATOM & CAI & & CT2 & -0.137 & & & & \\
\hline ATOM & $\mathrm{HOS}$ & & HA & 0.052 & & & & \\
\hline $\begin{array}{l}\text { ATOM } \\
!\end{array}$ & $\mathrm{HOC}$ & & $\mathrm{HA}$ & 0.057 & & & & \\
\hline BOND & CHA & HHA & $\mathrm{CHA}$ & $\mathrm{C} 1 \mathrm{~A}$ & CHA & $C 4 \mathrm{D}$ & $\mathrm{CGA}$ & $01 \mathrm{~A}$ \\
\hline BOND & $N_{-} A$ & H_A & N_A & $\mathrm{C} 1 \mathrm{~A}$ & N_A & $\mathrm{C} 4 \mathrm{~A}$ & $\mathrm{~N}_{-} \mathrm{B}$ & C4B \\
\hline BOND & $\mathrm{C} 1 \mathrm{~A}$ & $\mathrm{C} 2 \mathrm{~A}$ & $\mathrm{C} 2 \mathrm{~A}$ & C3A & $\mathrm{C} 2 \mathrm{~A}$ & $\mathrm{CAA}$ & C3B & C4B \\
\hline BOND & C3A & $\mathrm{C} 4 \mathrm{~A}$ & C3A & CMA & C4A & CHB & CMB & HB3 \\
\hline BOND & CMA & HA 1 & CMA & HA2 & CMA & HA3 & $\mathrm{CBB}$ & HV2 \\
\hline BOND & CAA & HO5 & CAA & HO6 & CAA & $\mathrm{CBA}$ & $\mathrm{CGA}$ & $02 \mathrm{~A}$ \\
\hline BOND & $\mathrm{CBA}$ & HO1 & CBA & HO2 & CBA & CGA & CMC & HE3 \\
\hline BOND & CHB & $\mathrm{C} 1 \mathrm{~B}$ & N_B & H_B & N_B & $\mathrm{C} 1 \mathrm{~B}$ & CMC & HE2 \\
\hline BOND & C1B & $\mathrm{C} 2 \mathrm{~B}$ & C2B & C3B & C2B & CMB & $\mathrm{CAC}$ & CBC \\
\hline BOND & C4B & O_B & CMB & HB1 & CMB & HB2 & C3B & $\mathrm{CAB}$ \\
\hline BOND & $\mathrm{CAB}$ & HAB & CAB & CBB & CBB & HV1 & CMD & HD3 \\
\hline BOND & $\mathrm{N}_{-} \mathrm{C}$ & $\mathrm{H}_{-} \mathrm{C}$ & $\mathrm{N}_{-} \mathrm{C}$ & $\mathrm{C} 1 \mathrm{C}$ & $\mathrm{N}_{-} \mathrm{C}$ & $\mathrm{C} 4 \mathrm{C}$ & CGD & 01D \\
\hline BOND & $\mathrm{C} 1 \mathrm{C}$ & $\mathrm{C} 2 \mathrm{C}$ & $\mathrm{C} 1 \mathrm{C}$ & O_C & $\mathrm{C} 2 \mathrm{C}$ & $\mathrm{H} 2 \mathrm{C}$ & CGD & O2D \\
\hline BOND & $\mathrm{C} 2 \mathrm{C}$ & C3C & $\mathrm{C} 2 \mathrm{C}$ & CMC & CMC & HE1 & & \\
\hline BOND & C3C & $\mathrm{C} 4 \mathrm{C}$ & C3C & $\mathrm{CAC}$ & CAC & $\mathrm{HAC}$ & & \\
\hline BOND & $\mathrm{CBC}$ & HL1 & CBC & HL2 & CHB & HHB & & \\
\hline BOND & $\mathrm{C} 4 \mathrm{C}$ & CHD & CHD & HHD & CHD & C1D & & \\
\hline BOND & N_D & C1D & N_D & C4D & & & & \\
\hline BOND & C1D & C2D & C2D & C3D & C3D & C4D & & \\
\hline BOND & C2D & CMD & CMD & HD1 & CMD & HD2 & & \\
\hline
\end{tabular}




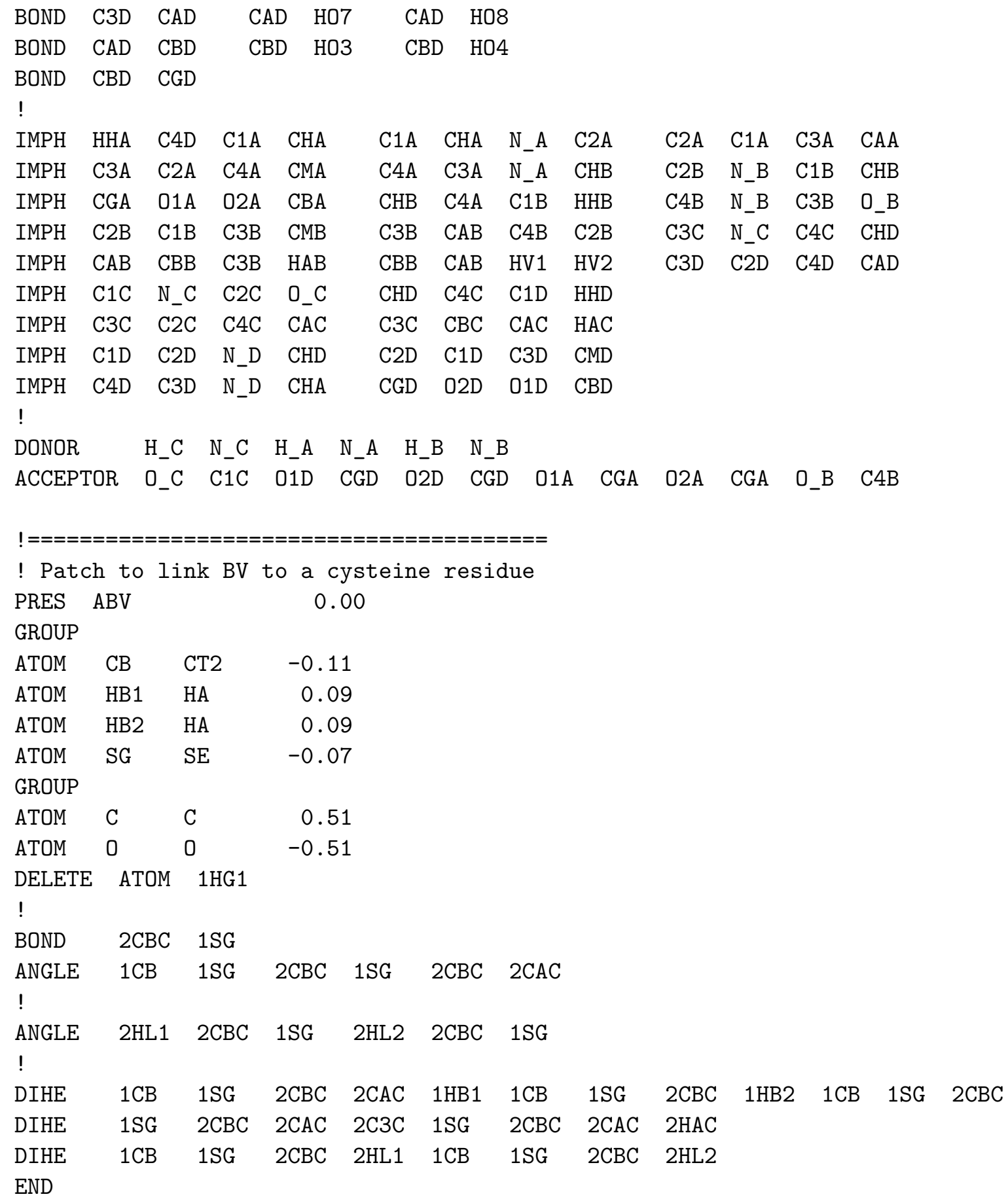


Figure S16: Parameter file for the CHARMM force field describing the biliverdin chromophore deprotonated at pyrrole ring $\mathrm{B}$, based on the previous parameters for the fully protonated chromophore. ${ }^{9,10}$

$\begin{array}{llll}* \text { B B-deprotonated chromophore } \\ * \\ \text { BONDS } & & & \\ \text { NR1 } & \text { CPA } & 377.200 & 1.3817 \\ \text { NR1 } & \text { C } & 260.000 & 1.4190 \\ \text { CT2 } & \text { CPM } & 230.000 & 1.4830 \\ \text { NR1 } & \text { CA } & 377.200 & 1.4117 \\ \text { SE } & \text { CT2 } & 198.000 & 1.8180 \\ \text { CPY1 } & \text { CA } & 305.000 & 1.4772 \\ \text { CT1 } & \text { CPY1 } & 230.000 & 1.4907 \\ \text { CPM } & \text { CPY1 } & 360.000 & 1.3266 \\ \text { CPY2 } & \text { CA } & 360.000 & 1.3800 \\ \text { HA } & \text { CPY2 } & 367.600 & 1.0902 \\ \text { CPY2 } & \text { CPA } & 360.000 & 1.4455 \\ \text { CPY3 } & \text { CA } & 360.000 & 1.3676 \\ \text { HA } & \text { CPY3 } & 367.600 & 1.0900 \\ \text { CPY3 } & \text { CPA } & 360.000 & 1.4225 \\ \text { CPY4 } & \text { CPA } & 299.800 & 1.4052 \\ \text { CPY4 } & \text { CPB } & 340.700 & 1.4018 \\ \text { CT2 } & \text { CPY4 } & 230.000 & 1.4946 \\ \text { CPY5 } & \text { CA } & 305.000 & 1.4620 \\ \text { CT3 } & \text { CPY5 } & 230.000 & 1.4850 \\ \text { CPY6 } & \text { C } & 250.000 & 1.4711 \\ \text { CPY6 } & \text { CE1 } & 450.000 & 1.4290 \\ \text { CPY6 } & \text { CPY5 } & 305.000 & 1.3470\end{array}$

\begin{tabular}{|c|c|c|c|c|c|c|}
\hline \multicolumn{7}{|c|}{ ANGLES } \\
\hline NR1 & $\mathrm{CPA}$ & $\mathrm{CPB}$ & 122.00 & 110.000 & & \\
\hline CPA & NR1 & $\mathrm{CPA}$ & 139.30 & 116.300 & & \\
\hline $\mathrm{H}$ & NR1 & $\mathrm{CPA}$ & 30.000 & 125.50 & 20.00 & 2.15000 \\
\hline CPM & CPA & NR1 & 88.000 & 131.800 & & \\
\hline NR1 & $\mathrm{C}$ & 0 & 80.000 & 118.000 & & \\
\hline $\mathrm{C}$ & NR1 & $\mathrm{H}$ & 34.000 & 123.000 & & \\
\hline NR1 & $\mathrm{C}$ & CT1 & 20.000 & 112.500 & & \\
\hline HA & CT2 & CPM & 49.300 & 107.500 & & \\
\hline $\mathrm{HA}$ & CPM & CT2 & 34.500 & 110.10 & 22.53 & 2.17900 \\
\hline $\mathrm{C}$ & NR1 & $\mathrm{CA}$ & 50.000 & 133.50 & & \\
\hline $\mathrm{H}$ & NR1 & $\mathrm{CA}$ & 30.000 & 125.50 & 20.00 & 2.15000 \\
\hline
\end{tabular}




\begin{tabular}{|c|c|c|c|c|}
\hline СТ2 & $\mathrm{SE}$ & CT2 & 34.000 & 95.000 \\
\hline $\mathrm{SE}$ & CT2 & CPM & 58.000 & 112.500 \\
\hline SE & CT2 & CT1 & 58.000 & 112.500 \\
\hline $\mathrm{SE}$ & CT2 & HA & 38.000 & 111.000 \\
\hline $\mathrm{HA}$ & CPM & CPY1 & 12.700 & 117.440 \\
\hline СТ2 & CPM & CPY1 & 45.800 & 117.490 \\
\hline NR1 & $\mathrm{CA}$ & CPY1 & 122.00 & 115.000 \\
\hline CT1 & CPY1 & CPM & 45.80 & 116.600 \\
\hline CT1 & CPY1 & $\mathrm{CA}$ & 45.80 & 128.000 \\
\hline CPY1 & CT1 & $\mathrm{C}$ & 52.00 & 113.700 \\
\hline $\mathrm{HA}$ & CT1 & CPY1 & 49.30 & 107.500 \\
\hline СТ3 & CT1 & CPY1 & 51.80 & 107.500 \\
\hline CPM & CPY1 & $\mathrm{CA}$ & 61.60 & 124.100 \\
\hline CPY2 & $\mathrm{CPA}$ & NR1 & 88.00 & 112.390 \\
\hline CPY2 & $\mathrm{CPA}$ & $\mathrm{CPB}$ & 61.60 & 124.070 \\
\hline CPY2 & $\mathrm{CA}$ & NR1 & 88.00 & 129.000 \\
\hline $\mathrm{CA}$ & CPY2 & CPA & 94.20 & 127.000 \\
\hline $\mathrm{HA}$ & CPY2 & CPA & 12.70 & 117.440 \\
\hline $\mathrm{HA}$ & CPY2 & $\mathrm{CA}$ & 12.70 & 117.440 \\
\hline CPY3 & $\mathrm{CA}$ & NR1 & 88.00 & 124.390 \\
\hline CPY1 & $\mathrm{CA}$ & CPY3 & 61.60 & 127.570 \\
\hline $\mathrm{CA}$ & СРY3 & $\mathrm{CPA}$ & 94.20 & 122.800 \\
\hline $\mathrm{HA}$ & СРY3 & CPA & 12.70 & 117.440 \\
\hline CPY3 & CPA & NR1 & 88.00 & 124.390 \\
\hline CPY3 & CPA & $\mathrm{CPB}$ & 61.60 & 125.070 \\
\hline $\mathrm{HA}$ & СРY3 & $\mathrm{CA}$ & 12.70 & 117.440 \\
\hline CPM & CPA & CPY4 & 61.60 & 132.500 \\
\hline NR1 & CPA & CPY4 & 122.00 & 111.540 \\
\hline CPB & CPY4 & CPA & 30.80 & 136.010 \\
\hline CT2 & CPY4 & $\mathrm{CPB}$ & 65.00 & 126.750 \\
\hline CPY4 & $\mathrm{CPB}$ & $\mathrm{CPA}$ & 30.80 & 145.010 \\
\hline CT3 & $\mathrm{CPB}$ & CPY4 & 65.00 & 126.750 \\
\hline CT2 & CT2 & CPY4 & 70.00 & 114.700 \\
\hline $\mathrm{HA}$ & CT2 & CPY4 & 50.00 & 109.500 \\
\hline CT2 & CPY4 & $\mathrm{CPA}$ & 65.00 & 126.740 \\
\hline NR1 & $\mathrm{CA}$ & CPY5 & 122.00 & 112.400 \\
\hline CPY5 & $\mathrm{CA}$ & CPY2 & 61.60 & 124.970 \\
\hline CT3 & CPY5 & $\mathrm{CA}$ & 45.80 & 115.900 \\
\hline $\mathrm{HA}$ & CT3 & CPY5 & 49.30 & 107.500 \\
\hline NR1 & C & CPY6 & 20.00 & 109.500 \\
\hline CPY6 & C & 0 & 80.00 & 118.000 \\
\hline CT3 & CPY5 & CPY6 & 45.80 & 122.300 \\
\hline $\mathrm{C}$ & CPY6 & CPY5 & 52.00 & 116.000 \\
\hline $\mathrm{C}$ & CPY6 & CE1 & 70.00 & 114.490 \\
\hline CPY5 & CPY6 & CE1 & 70.00 & 126.740 \\
\hline HE1 & CE1 & CPY6 & 50.00 & 120.000 \\
\hline
\end{tabular}




$\begin{array}{lllll}\text { CE2 } & \text { CE1 } & \text { CPY6 } & 40.00 & 117.600 \\ \text { CA } & \text { CPY5 } & \text { CPY6 } & 40.00 & 116.500\end{array}$

\begin{tabular}{|c|c|c|c|c|c|c|}
\hline \multicolumn{7}{|c|}{ DIHEDRALS } \\
\hline $\mathrm{H}$ & NR1 & $\mathrm{CPA}$ & $\mathrm{CPB}$ & 1.0000 & 2 & 180.00 \\
\hline $\mathrm{H}$ & NR1 & $\mathrm{CPA}$ & CPM & 1.0000 & 2 & 180.00 \\
\hline CPM & $\mathrm{CPA}$ & NR1 & $\mathrm{CPA}$ & 14.0000 & 2 & 180.00 \\
\hline CPA & NR1 & $\mathrm{CPA}$ & $\mathrm{CPB}$ & 14.0000 & 2 & 180.00 \\
\hline NR1 & $\mathrm{C}$ & CT1 & HA & 0.1900 & 3 & 0.00 \\
\hline 0 & $\mathrm{C}$ & CT1 & $\mathrm{HA}$ & 0.0000 & 3 & 180.00 \\
\hline NR1 & $\mathrm{C}$ & CT1 & СТ3 & 0.0000 & 1 & 0.00 \\
\hline $\mathrm{H}$ & NR1 & $\mathrm{C}$ & CT1 & 2.5000 & 2 & 180.00 \\
\hline HA & CT2 & CPM & $\mathrm{HA}$ & 0.1600 & 3 & 100.00 \\
\hline $\mathrm{H}$ & NR1 & $\mathrm{C}$ & 0 & 2.5000 & 2 & 180.00 \\
\hline $\mathrm{CA}$ & NR1 & $\mathrm{C}$ & 0 & 2.7500 & 2 & 180.00 \\
\hline $\mathrm{CA}$ & NR1 & $\mathrm{C}$ & $\mathrm{CT} 1$ & 2.7500 & 2 & 180.00 \\
\hline HA & СТ3 & CT1 & $\mathrm{C}$ & 0.0000 & 6 & 0.00 \\
\hline CPA & $\mathrm{CPB}$ & $\mathrm{CPB}$ & CT2 & 14.0000 & 2 & 180.00 \\
\hline CPA & $\mathrm{CPB}$ & $\mathrm{CPB}$ & CT3 & 14.0000 & 2 & 180.00 \\
\hline SE & CT2 & CPM & $\mathrm{CA}$ & 0.0000 & 6 & 0.00 \\
\hline CT1 & CT2 & $\mathrm{SE}$ & CT2 & 0.2400 & 1 & 180.00 \\
\hline $\mathrm{HA}$ & CT2 & $\mathrm{SE}$ & CT2 & 0.2800 & 3 & 0.00 \\
\hline $\mathrm{SE}$ & CT2 & CPM & $\mathrm{HA}$ & 0.0100 & 3 & 0.00 \\
\hline HS & $\mathrm{SE}$ & CT2 & CPM & 0.2700 & 3 & 0.00 \\
\hline NR1 & $\mathrm{CA}$ & CPY1 & $\mathrm{CPM}$ & 3.0000 & 2 & 180.00 \\
\hline CPM & CPY1 & CT1 & $\mathrm{C}$ & 3.0000 & 3 & 0.00 \\
\hline $\mathrm{HA}$ & CT1 & CPY1 & CPM & 0.0400 & 3 & 0.00 \\
\hline CT3 & CT1 & CPY1 & CPM & 3.1000 & 2 & 180.00 \\
\hline HA & CPM & CPY1 & CT1 & 1.2000 & 2 & 180.00 \\
\hline $\mathrm{C}$ & NR1 & $\mathrm{CA}$ & CPY1 & 0.0000 & 2 & 0.00 \\
\hline $\mathrm{CA}$ & CPY1 & CT1 & $\mathrm{C}$ & 0.0400 & 3 & 0.00 \\
\hline $\mathrm{HA}$ & CT1 & CPY1 & $\mathrm{CA}$ & 0.0400 & 3 & 0.00 \\
\hline NR1 & $\mathrm{C}$ & CT1 & CPY1 & 0.0000 & 1 & 0.00 \\
\hline NR1 & $\mathrm{CA}$ & CPY1 & CT1 & 0.1900 & 3 & 0.00 \\
\hline $\mathrm{H}$ & NR1 & $\mathrm{CA}$ & CPY1 & 1.0000 & 2 & 180.00 \\
\hline CT3 & CT1 & CPY1 & $\mathrm{CA}$ & 3.1000 & 2 & 180.00 \\
\hline HA & CT2 & CPM & CPY1 & 0.0000 & 3 & 0.00 \\
\hline 0 & $\mathrm{C}$ & CT1 & CPY1 & 1.4000 & 1 & 180.00 \\
\hline CT2 & $\mathrm{CPM}$ & CPY1 & CT1 & 3.1000 & 2 & 180.00 \\
\hline CT1 & CPY1 & $\mathrm{CA}$ & $\mathrm{CPM}$ & 3.1000 & 2 & 180.00 \\
\hline HA & CPM & CPY1 & $\mathrm{CA}$ & 0.0000 & 2 & 0.00 \\
\hline HA & CPM & $\mathrm{CA}$ & CPY1 & 0.0000 & 2 & 0.00 \\
\hline CPY2 & $\mathrm{CPA}$ & NR1 & $\mathrm{CPA}$ & 14.0000 & 2 & 180.00 \\
\hline NR1 & $\mathrm{CPA}$ & CPY2 & $\mathrm{HA}$ & 1.9000 & 2 & 180.00 \\
\hline $\mathrm{H}$ & NR1 & $\mathrm{CPA}$ & CPY2 & 0.0000 & 2 & 180.00 \\
\hline
\end{tabular}




\begin{tabular}{|c|c|c|c|c|c|c|}
\hline CPB & CPA & CPY2 & $\mathrm{HA}$ & 0.0000 & 2 & 180.00 \\
\hline CPA & CPY2 & $\mathrm{CA}$ & NR1 & 3.0000 & 2 & 180.00 \\
\hline C & NR1 & $\mathrm{CA}$ & CPY2 & 0.0000 & 2 & 0.00 \\
\hline NR1 & $\mathrm{CA}$ & CPY2 & $\mathrm{HA}$ & 0.0000 & 2 & 0.00 \\
\hline $\mathrm{H}$ & NR1 & $\mathrm{CA}$ & CPY2 & 1.0000 & 2 & 180.00 \\
\hline NR1 & CPA & CPY2 & $\mathrm{CA}$ & 0.0000 & 2 & 180.00 \\
\hline CPY3 & CPA & NR1 & $\mathrm{CPA}$ & 14.0000 & 2 & 180.00 \\
\hline NR1 & CPA & CPY3 & HA & 0.1900 & 3 & 0.00 \\
\hline $\mathrm{H}$ & NR1 & CPA & СРY3 & 1.0000 & 2 & 180.00 \\
\hline CPB & CPA & CPY3 & HA & 0.0000 & 2 & 0.00 \\
\hline CPA & СРY3 & $\mathrm{CA}$ & NR1 & 3.0000 & 2 & 180.00 \\
\hline C & NR1 & $\mathrm{CA}$ & СРY3 & 0.0000 & 2 & 0.00 \\
\hline NR1 & $\mathrm{CA}$ & СРYЗ & $\mathrm{HA}$ & 0.0000 & 2 & 0.00 \\
\hline $\mathrm{H}$ & NR1 & $\mathrm{CA}$ & СРY3 & 1.0000 & 2 & 180.00 \\
\hline NR1 & CPA & СРY3 & $\mathrm{CA}$ & 3.0000 & 2 & 180.00 \\
\hline CPM & CPY1 & $\mathrm{CA}$ & СРY3 & 3.1000 & 2 & 180.00 \\
\hline CPY1 & $\mathrm{CA}$ & СРҮЗ & $\mathrm{HA}$ & 3.1000 & 2 & 180.00 \\
\hline CT1 & CPY1 & $\mathrm{CA}$ & СРY3 & 3.1000 & 2 & 180.00 \\
\hline CPM & CPA & CPY4 & $\mathrm{CPB}$ & 0.0000 & 2 & 0.00 \\
\hline CPM & CPA & CPY4 & СT2 & 0.0000 & 2 & 0.00 \\
\hline CPA & CPY 4 & $\mathrm{CPB}$ & CT3 & 0.0000 & 2 & 180.00 \\
\hline CPA & CPY4 & СT2 & СT2 & 0.0000 & 6 & 0.00 \\
\hline CPA & CPY4 & CT2 & $\mathrm{HA}$ & 0.0000 & 6 & 0.00 \\
\hline NR1 & CPA & CPY4 & $\mathrm{CPB}$ & 0.0000 & 2 & 0.00 \\
\hline NR1 & $\mathrm{CPA}$ & CPY4 & CT2 & 0.0000 & 2 & 0.00 \\
\hline $\mathrm{H}$ & NR1 & CPA & CPY4 & 0.0000 & 2 & 0.00 \\
\hline CPY4 & CPA & NR1 & $\mathrm{CPA}$ & 14.0000 & 2 & 180.00 \\
\hline $\mathrm{CPB}$ & CPY4 & CT2 & СT2 & 0.0000 & 6 & 0.00 \\
\hline $\mathrm{CPB}$ & CPY 4 & CT2 & $\mathrm{HA}$ & 0.0000 & 6 & 0.00 \\
\hline CPA & CPY4 & $\mathrm{CPB}$ & $\mathrm{CPA}$ & 14.0000 & 2 & 180.00 \\
\hline CPA & $\mathrm{CPB}$ & CPY4 & CT2 & 1.0000 & 2 & 180.00 \\
\hline СТ3 & $\mathrm{CPB}$ & CPY4 & СT2 & 0.0000 & 2 & 180.00 \\
\hline C & NR1 & $\mathrm{CA}$ & CPY5 & 0.0000 & 2 & 0.00 \\
\hline $\mathrm{CA}$ & CPY5 & СТ3 & $\mathrm{HA}$ & 0.0000 & 3 & 0.00 \\
\hline CPY5 & $\mathrm{CA}$ & CPY2 & HA & 0.0000 & 2 & 0.00 \\
\hline CPY2 & $\mathrm{CA}$ & CPY5 & СT3 & 3.1000 & 2 & 180.00 \\
\hline NR1 & $\mathrm{CA}$ & CPY5 & СТ3 & 3.0000 & 2 & 180.00 \\
\hline $\mathrm{H}$ & NR1 & $\mathrm{CA}$ & CPY5 & 1.0000 & 2 & 180.00 \\
\hline CE1 & $\mathrm{CA}$ & CPY5 & $\mathrm{CA}$ & 3.1000 & 2 & 180.00 \\
\hline $\mathrm{CA}$ & CPY5 & CPY6 & $\mathrm{C}$ & 0.0400 & 3 & 0.00 \\
\hline СТ3 & CPY5 & CPY6 & $\mathrm{C}$ & 14.0000 & 3 & 0.00 \\
\hline $\mathrm{C}$ & CPY6 & CE1 & HE1 & 0.0000 & 2 & 180.00 \\
\hline C & CPY6 & CE1 & $\mathrm{CE} 2$ & 1.0000 & 2 & 180.00 \\
\hline NR1 & C & CPY6 & CPY5 & 0.0000 & 1 & 0.00 \\
\hline NR1 & C & CPY6 & CE1 & 0.0000 & 1 & 0.00 \\
\hline NR1 & $\mathrm{CA}$ & CPY5 & CPY6 & 3.0000 & 2 & 180.00 \\
\hline
\end{tabular}




\begin{tabular}{|c|c|c|c|c|c|c|}
\hline $\mathrm{H}$ & NR1 & C & CPY6 & 2.5000 & 2 & 180.00 \\
\hline $\mathrm{CA}$ & NR1 & $\mathrm{C}$ & CPY6 & 14.0000 & 2 & 180.00 \\
\hline CE1 & CPY6 & CPY5 & $\mathrm{CA}$ & 3.1000 & 2 & 180.00 \\
\hline 0 & $\mathrm{C}$ & CPY6 & CPY5 & 0.4000 & 1 & 180.00 \\
\hline CPY5 & CPY6 & CE1 & HE1 & 1.0000 & 2 & 180.00 \\
\hline CPY6 & CPY5 & $\mathrm{CA}$ & CPY2 & 1.1000 & 2 & 180.00 \\
\hline CPY6 & CPY5 & СТ3 & $\mathrm{HA}$ & 0.0000 & 3 & 0.00 \\
\hline CPY6 & CE1 & $\mathrm{CE} 2$ & HE2 & 5.2000 & 2 & 180.00 \\
\hline 0 & C & CPY6 & CE1 & 1.4000 & 1 & 0.00 \\
\hline $\begin{array}{l}\text { CE1 } \\
!\end{array}$ & CPY6 & CPY5 & СТ3 & 3.1000 & 2 & 180.00 \\
\hline \multicolumn{7}{|c|}{$\begin{array}{l}\text { ! multip } \\
\text { ! VINYL }\end{array}$} \\
\hline CPY5 & CPY6 & CE1 & CE2 & 0.90 & 1 & 0.00 \\
\hline CPY5 & CPY6 & CE1 & CE2 & 2.35 & 2 & 180.00 \\
\hline $\begin{array}{l}\text { CPY5 } \\
!\end{array}$ & CPY6 & \multicolumn{4}{|c|}{ ! } & 0.00 \\
\hline \multicolumn{7}{|c|}{ ! DB pyrrol-pyrrolinone ring A-B } \\
\hline CPY1 & $\mathrm{CA}$ & CPY3 & $\mathrm{CPA}$ & 4.8 & 1 & 0.0 \\
\hline CPY1 & $\mathrm{CA}$ & CPY3 & CPA & 16.0 & 2 & 178.0 \\
\hline $\begin{array}{l}\text { CPY1 } \\
!\end{array}$ & \multicolumn{5}{|c|}{$!$} & 160.0 \\
\hline \multicolumn{7}{|c|}{ ! EB pyrrol-pyrrolinone ring $A-B$} \\
\hline $\mathrm{CA}$ & CPY3 & $\mathrm{CPA}$ & $\mathrm{CPB}$ & 2.0 & 3 & 180.0 \\
\hline $\mathrm{CA}$ & CPY3 & CPA & $\mathrm{CPB}$ & 4.0 & 2 & 180.0 \\
\hline $\begin{array}{l}\text { CA } \\
!\end{array}$ & CPY3 & $\mathrm{CPA}$ & $\mathrm{CPB}$ & 6.0 & 1 & 0.0 \\
\hline \multicolumn{7}{|c|}{ ! pyrrol-pyrrol 1} \\
\hline CPY4 & $\mathrm{CPA}$ & CPM & $\mathrm{CPA}$ & 18.0 & 2 & 183.0 \\
\hline CPY4 & CPA & CPM & $\mathrm{CPA}$ & 4.5 & 1 & 2.0 \\
\hline $\begin{array}{l}\text { CPY4 } \\
!\end{array}$ & $\mathrm{CPA}$ & CPM & $\mathrm{CPA}$ & 5.0 & 3 & 190.0 \\
\hline \multicolumn{7}{|c|}{ ! pyrrol-pyrrol 2} \\
\hline $\mathrm{CPB}$ & $\mathrm{CPA}$ & CPM & $\mathrm{CPA}$ & 1.5 & 3 & 180.0 \\
\hline $\mathrm{CPB}$ & $\mathrm{CPA}$ & CPM & $\mathrm{CPA}$ & 5.0 & 2 & 180.0 \\
\hline \multicolumn{7}{|l|}{$!$} \\
\hline \multicolumn{7}{|c|}{ ! DB pyrrol-pyrrolinone ring C-D } \\
\hline $\mathrm{CPA}$ & CPY2 & $\mathrm{CA}$ & CPY5 & 11.8 & 1 & 0.0 \\
\hline \multicolumn{7}{|l|}{$!$} \\
\hline \multicolumn{7}{|c|}{ ! EB pyrrol-pyrrolinone ring C-D } \\
\hline CPB & $\mathrm{CPA}$ & CPY2 & $\mathrm{CA}$ & 2.0 & 3 & 0.0 \\
\hline $\mathrm{CPB}$ & $\mathrm{CPA}$ & CPY2 & $\mathrm{CA}$ & 4.4 & 2 & 138.0 \\
\hline $\begin{array}{l}\text { CPB } \\
!\end{array}$ & $\mathrm{CPA}$ & CPY2 & $\mathrm{CA}$ & 2.1 & 1 & 243.0 \\
\hline
\end{tabular}




\begin{tabular}{llllrlr}
\multicolumn{2}{l}{ linking } & fragment & & & & \\
CT2 & SE & CT2 & CPM & 0.7 & 3 & 10.00 \\
CT2 & SE & CT2 & CPM & 1.1 & 1 & 88.00 \\
SE & CT2 & CPM & CPY1 & 1.4 & 2 & 45.00 \\
CT2 & CPM & CPY1 & CA & 2.4 & 2 & 180.00 \\
CT2 & CPM & CPY1 & CA & 16.4 & 1 & 4.00
\end{tabular}

\begin{tabular}{|c|c|c|c|c|c|c|}
\hline \multicolumn{7}{|c|}{ IMPROPER } \\
\hline CPA & $\mathrm{CPB}$ & NR1 & CPM & 200.0000 & 0 & 0.0000 \\
\hline HE2 & HE2 & CE1 & CE2 & 3.0000 & 0 & 0.0000 \\
\hline $\mathrm{CD}$ & $\mathrm{OB}$ & $\mathrm{OH} 1$ & CT2 & 96.0000 & 0 & 0.0000 \\
\hline CPB & $\mathrm{CPB}$ & CPA & CT2 & 90.0000 & 0 & 0.0000 \\
\hline $\mathrm{CPB}$ & $\mathrm{CPA}$ & $\mathrm{CPB}$ & СT2 & 90.0000 & 0 & 0.0000 \\
\hline CPY1 & CT1 & $\mathrm{CA}$ & CPM & 0.0000 & 0 & 0.0000 \\
\hline CPY1 & CT2 & $\mathrm{CPM}$ & $\mathrm{HA}$ & 29.4000 & 0 & 180.000 \\
\hline CPA & $\mathrm{CPB}$ & NR1 & CPY2 & 140.0000 & 0 & 0.0000 \\
\hline CPY2 & $\mathrm{CPA}$ & $\mathrm{CA}$ & $\mathrm{HA}$ & 29.4000 & 0 & 0.0000 \\
\hline CPA & $\mathrm{CPB}$ & NR1 & СРY3 & 145.000 & 0 & 0.0000 \\
\hline $\mathrm{HA}$ & $\mathrm{CPA}$ & $\mathrm{CA}$ & СРY3 & 29.4000 & 0 & 0.0000 \\
\hline CPY1 & NR1 & $\mathrm{CA}$ & СРY3 & 140.0000 & 0 & 180.00 \\
\hline $\mathrm{CPA}$ & CPM & NR1 & CPY4 & 61.0000 & 0 & 0.0000 \\
\hline CPY4 & $\mathrm{CPA}$ & $\mathrm{CPB}$ & CT2 & 64.0000 & 0 & 0.0000 \\
\hline CPB & CPY4 & CPA & CT3 & 90.0000 & 0 & 0.0000 \\
\hline CPY5 & NR1 & $\mathrm{CA}$ & CPY2 & 7.0000 & 0 & 180.000 \\
\hline CPY5 & $\mathrm{C}$ & $\mathrm{CA}$ & CE1 & 90.0000 & 0 & 180.000 \\
\hline CPY5 & $X$ & $\mathrm{X}$ & СТ3 & 0.0000 & 0 & 0.0000 \\
\hline CPY6 & $\mathrm{CE} 1$ & $\mathrm{C}$ & CPY5 & 180.0000 & 0 & 0.0000 \\
\hline HE1 & $\mathrm{X}$ & $\mathrm{X}$ & CE1 & 3.0000 & 0 & 0.0000 \\
\hline
\end{tabular}

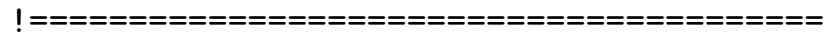

NONBONDED nbxmod 5 atom cdiel shift vatom vdistance vswitch cutnb 14.0 ctofnb 12.0 ctonnb 10.0 eps 1.0 e14fac 1.0 wmin 1.5 $\begin{array}{llll}\text { CPY } 1 & 0.000000 & -0.070000 & 1.992400\end{array}$

$\begin{array}{llll}\text { CPY2 } & 0.000000 & -0.090000 & 1.800000\end{array}$

$\begin{array}{llll}\text { CPY3 } & 0.000000 & -0.090000 & 1.800000\end{array}$

$\begin{array}{llll}\text { CPY4 } & 0.000000 & -0.090000 & 1.800000\end{array}$

$\begin{array}{llll}\text { CPY5 } & 0.000000 & -0.070000 & 1.992400\end{array}$

$\begin{array}{llll}\text { CPY6 } & 0.000000 & -0.070000 & 1.992400\end{array}$

$\begin{array}{llll}\mathrm{SE} & 0.000000 & -0.470000 & 2.200000\end{array}$

END 


\section{S4 Chromophore dynamics and migration of water molecules in the situation at neutral $\mathrm{pH}$ and with the B-deprotonated chromophore.}

In this section, we examine a physiologically less likely situation, when the chromophore is deprotonated at the $\mathrm{B}$ pyrrole ring at neutral $\mathrm{pH}$ (see Fig. 3 in the main text for the ring definitions). Although the chromophore is likely fully protonated in the whole spectrum of $\mathrm{pH}$, as suggested by earlier experiments, the analysis of the B-deprotonated chromophore may still provide some insights into the dynamics of IFPs. As discussed in Section S2 (also see Fig. S13), the unbound biliverdin adopts a more planar geometry in its B-deprotonated form, which may favor the enhancement of fluorescence.

Similarly to the situation with the fully protonated chromophore, the most significant differences between the proteins are visible for dihedrals $\mathbf{1}$ and $\mathbf{2}$ (see Fig. S17). The planarity of dihedral angle 1 is calculated to be $12.6^{\circ}$ in $\operatorname{DrCBD}$ and decreases to $4.1^{\circ}$ in IFP2.0 (see Tab. S3). The rigidity of dihedral $\mathbf{2}$ does not show a clear trend, which is reminiscent of the simulation of the fully protonated chromophore. Interestingly, dihedral $\mathbf{1}$ is now consistently more planar and rigid in comparison to the case with the fully protonated chromophore (see Tab. 3 in the paper). Dihedral 2 shows a significant improvement of planarity on going from the parent protein $\left(\mu=17.9^{\circ}\right)$ to IFP2.0 $\left(\mu=-0.9^{\circ}\right)$, which is the most dramatic change in all simulations that we have performed. The fragments of the chromophore described by dihedral $\mathbf{2}$ display again a rather irregular rigidity depending on the protein. Nevertheless, these fragments appear most flexible in $\operatorname{DrCBD}(\sigma=12.4)$ and most rigid in IFP2.0 $(\sigma=8.4)$. Compared to the previous situation, dihedral 2 in the B-deprotonated chromophore is initially more distorted $\left(\mu=13.1^{\circ}\right.$ vs $\left.\mu=17.9^{\circ}\right)$, but shows a regular trend towards planarity with the increasing fluorescence. The rigidity of dihedral 2 appears comparable for both protonation states of biliverdin. The inner pyrrole 
rings described by dihedral angles 3 and $\mathbf{4}$ show similar dynamics as before. Dihedral $\mathbf{3}$ is predicted to be slightly more planar and rigid with the B-deprotonated chromophore. Dihedral 5 connecting rings $\mathrm{C}$ and $\mathrm{D}$ is now more displaced out of planarity, in particular for the intermediate IFPs. For example, the mean value of dihedral 5 in IFP1.4 is calculated to be $11.0^{\circ}$ and $16.1^{\circ}$ for the fully protonated and B-deprotonated chromophore, respectively. The flexibility of dihedral $\mathbf{5}$ does not change much between different protonation forms of biliverdin. Lastly, dihedral 6 is slightly more displaced out of planarity with the B-deprotonated chromophore, whereas its flexibility remains similar.

We have also analyzed the mobility of water molecules in the neighborhood of the B-deprotonated chromophore (see Fig. S18). In $\operatorname{DrCBD}$, the pyrrole water is promptly displaced from its crystallographic position and shows reasonable mobility inside the cavity. The water forms transient hydrogen bonds to the nitrogen atom of the deprotonated ring $\mathrm{B}$ of the chromophore, or to the carbonyl carbon atom at ring $\mathrm{A}$. At the same time, it maintains contact with other water molecules from the bulk solvent through a chain of hydrogen bonds. The closest of these waters can push the pyrrole water further towards the region between the rings, thus causing ring A to move out of planarity. After about 3 ns of simulation, the pyrrole water is displaced from its position and replaced by another water. Water replacements in the cavity recur during the rest of the simulation.

Unlike in $\operatorname{DrCBD}$, the pyrrole water in IFP1.0 is isolated from the solvent because His207 hinders access of solvent to the chromophore. His207 is $\epsilon$-protonated and forms a hydrogen bond to the carbonyl oxygen of the A pyrrole ring. This hydrogen bond remains in place throughout the simulation, although the His207 side-chain displays some flexibility. We do not observe any water exchange between the cavity of the chromophore and the outer solvent; the pyrrole water is permanently locked between the rings. After the first $0.5 \mathrm{~ns}$ of simulation, the pyrrole water establishes two hydrogen bonds, one to the $\delta$-nitrogen of His260 and another to the carbonyl oxygen at ring A. These bonds remain intact until the end of the simulation. 
In IFP1.4, the orientation of the His207 side-chain is different than in IFP1.0. Namely, the $\delta$-hydrogen now forms a hydrogen bond to the carbonyl oxygen of the protein backbone. The carbonyl oxygen at ring $\mathrm{A}$ is coordinated both by the pyrrole water and by solvent waters from the outer side. Some limited contact is possible between these solvent waters and the pyrrole water. The contact is improved after $8.5 \mathrm{~ns}$ of simulation when the His207 side chain rotates outwards and more solvent waters approach the cavity occupied by the pyrrole water. However, the exchange of water molecules, which was seen in $\operatorname{DrCBD}$, does not generally occur here. The transient opening of the cavity is followed by a prompt return of His207 to its previous conformation.

IFP2.0 is exceptional in the sense that His260 is calculated to be doubly protonated with the B-deprotonated chromophore at neutral pH (Fig. S8). The pyrrole water is initially shifted towards the solvent. The shift is likely triggered by the electrostatic repulsion from the additional $\delta$-proton of His260 or for sterical reasons. No direct contacts are visible between the pyrrole water and solvent waters, which may be due to the exposure of the hydrophobic part of the Thr207 side-chain towards the solvent and a different network of hydrogen bonds. However, the pyrrole water is promptly exchanged during the simulation by another water coming from the vicinity of ring A. This new water molecule remains locked between His260 and the pyrrole rings until the end of the simulation. Except for the initial replacement of the pyrrole water, no further exchange of water molecules is observed throughout the simulation. Overall, the mobility of water in IFP2.0 is predicted to be somewhat higher than in IFP1.0 and IFP1.4, but nevertheless noticeably lower than in DrCBD (see Fig. S18).

Comparison to the simulations with the fully protonated chromophore. We note that the overall picture of the simulations generally holds up regardless of the protonation state of the chromophore, with the exception of IFP2.0. The most intensive water exchange is observed in the case of $\operatorname{DrCBD}$ for both protonation states of biliverdin. In IFP1.0 and IFP1.4, the inner pyrrole water is always locked in the cavity of the chro- 
mophore and its contact with the solvent is hindered by His207. In IFP2.0, we observe a rather intensive water migration when the chromophore is fully protonated (see the discussion in the paper). However, this migration does not seem to displace the chromophore out of planarity, because Thr207 interacts only weakly with the chromophore. When the chromophore is in its B-deprotonated form, His260 is calculated to be fully protonated at neutral pH (see Fig. S8). In this situation, the dynamics of IFP2.0 resembles that of the other IFPs and the pyrrole water remains isolated from the solvent. 

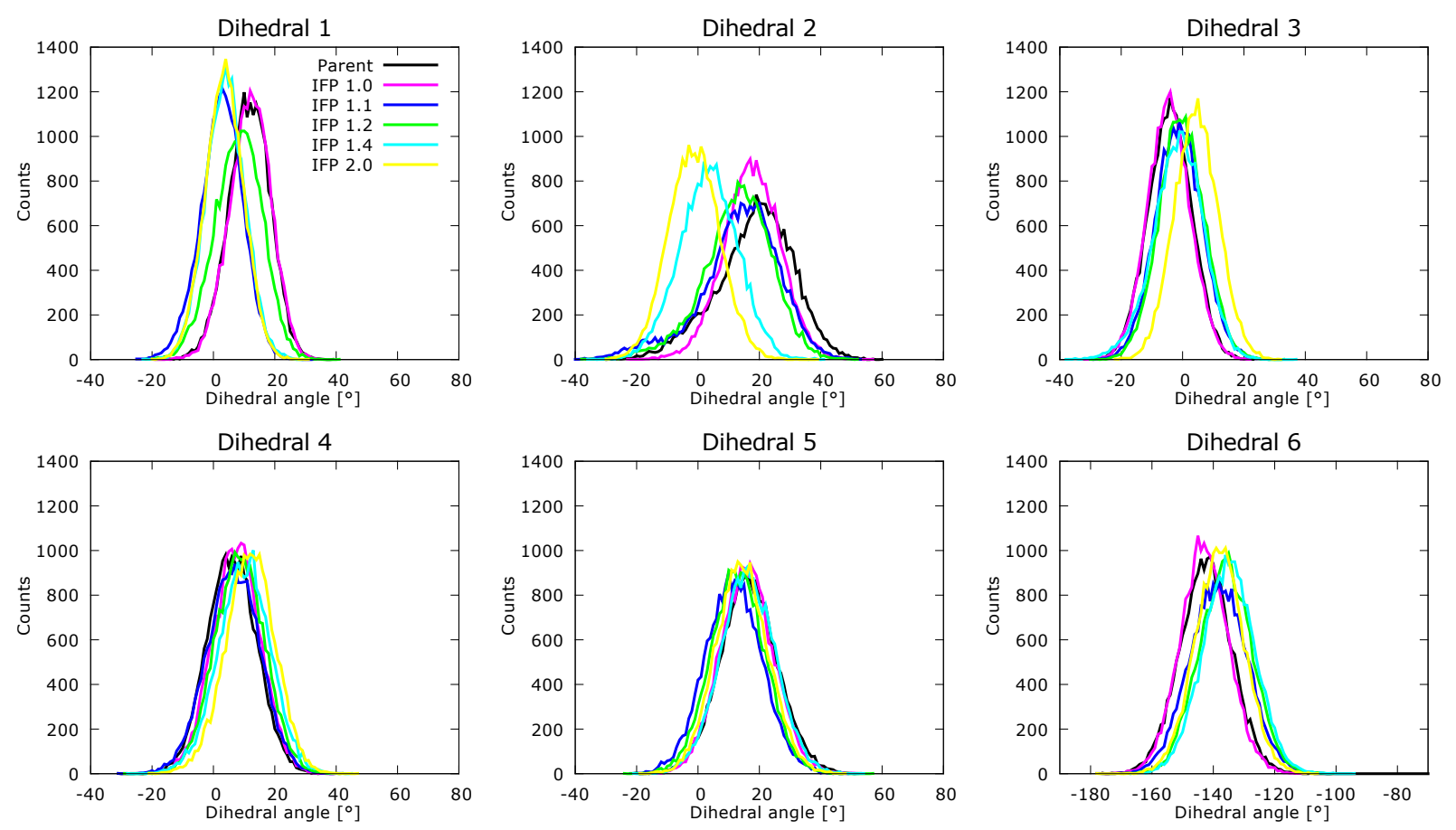

Figure S17: Statistical distributions of the six dihedral angles of the chromophore for all proteins. The simulations were performed at neutral $\mathrm{pH}$ and with the chromophore in its B-deprotonated form. See Fig. 3 in the paper for the definitions of the dihedrals. 


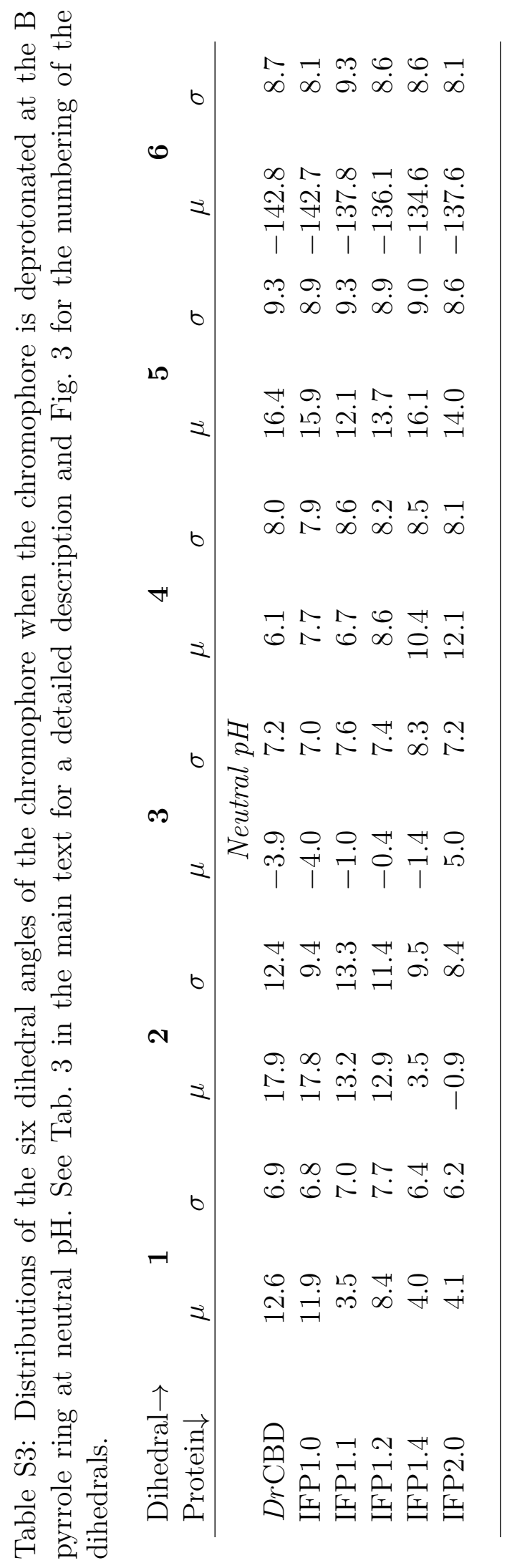




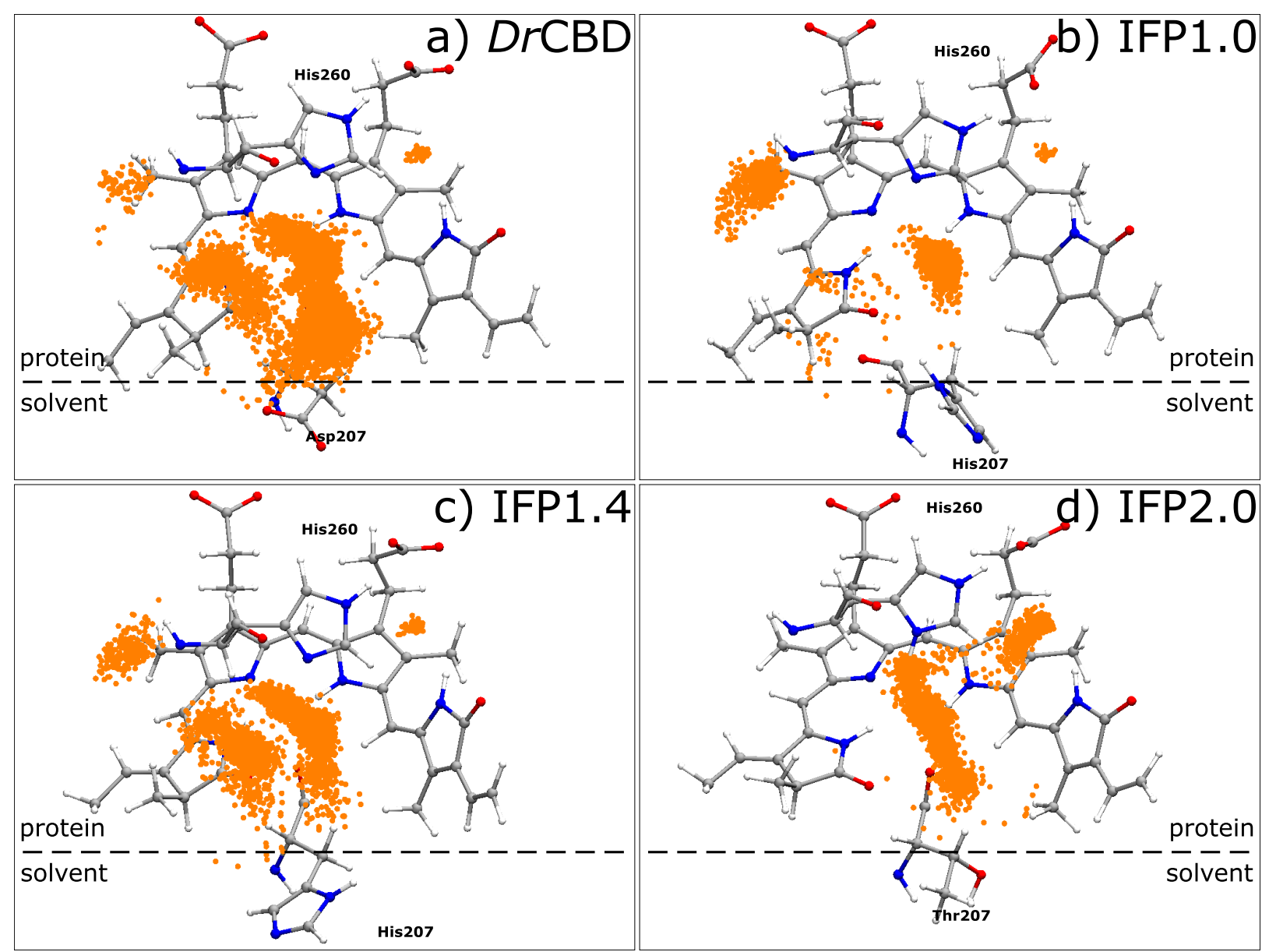

Figure S18: Mobility of water molecules inside the chromophore binding pocket in different proteins at $\mathrm{pH}=7$ and with the B-deprotonated chromophore. See Fig. 6 in the main text for details. 
Table S4: A list of animations showing the observed key events during the molecular dynamics simulations. In the animations, the chromophore and water molecules are shown in a ball-and-stick representation, while the surrounding residues, His260, Tyr263, Asp/His/Thr207 are shown in a licorice representation. His260 and Tyr260 are colored in lime and brown, respectively. For clarity, only water molecules within a radius of $7.0 \AA$ from the center of the chromophore are shown. To obtain a smooth animation and eliminate minor thermal motion, the coordinates of the system for each simulation frame were averaged over 5 consecutive frames. The animations were generated for the simulations at neutral $\mathrm{pH}$ and with the fully protonated chromophore. Since IFP1.0 and IFP1.4 have a similar dynamic behavior, only an animation of the latter protein is included.

\begin{tabular}{ll} 
Animation file & Description \\
\hline parent_wat_mobil.avi & Mobility of water in DrCBD \\
ifp14_lock_pyr_wat.avi & Locked pyrrole water, rotation of His207 in IFP1.4 \\
ifp20_wat_rel.avi & Release of the pyrrole water in IFP2.0 \\
\hline
\end{tabular}




\section{References}

[1] Larkin, M. A.; Blackshields, G.; Brown, N. P.; Chenna, R.; McGettigan, P. A.; McWilliam, H.; Valentin, F.; Wallace, I. M.; Wilm, A.; Lopez, R.; Thompson, J. D.; Gibson, T. J.; Higgins, D. G., Clustal W and Clustal X Version 2.0. Bioinformatics, 2007, 23, 2947-2948.

[2] Robert, X.; Gouet, P., Deciphering Key Features in Protein Structures with the New Endscript Server. Nucleic Acids Res., 2014, 42, 320-324.

[3] The PyMOL Molecular Graphics System, Version 1.3r1, Schrodinger, LLC. 2010.

[4] Velazquez Escobar, F.; Hildebrandt, T.; Utesch, T.; Schmitt, F. J.; Seuffert, I.; Michael, N.; Schulz, C.; Mroginski, M. A.; Friedrich, T.; Hildebrandt, P., Structural Parameters Controlling the Fluorescence Properties of Phytochromes. Biochemistry, 2014, 53, 20-29.

[5] Shu, X.; Royant, A.; Lin, M. Z.; Aguilera, T. A.; Lev-Ram, V.; Steinbach, P. A.; Tsien, R. Y., Mammalian Expression of Infrared Fluorescent Proteins Engineered From a Bacterial Phytochrome. Science, 2009, 324, 804-807.

[6] Ullmann, G. M.; Knapp, E. W., Electrostatic Models for Computing Protonation and Redox Equilibria in Proteins. Eur. Biophys. J., 1999, 28, 533-551.

[7] Liptak, M. D.; Shields, G. C., Accurate $\mathrm{p} K_{\mathrm{a}}$ Calculations for Carboxylic Acids Using Complete Basis Set and Gaussian-N Models Combined with CPCM Continuum Solvation Methods. J. Am. Chem. Soc., 2001, 123, 7314-7319.

[8] Muckerman, J. T.; Skone, J. H.; Ning, M.; Wasada-Tsutsui, Y., Toward the Accurate Calculation of $\mathrm{p} K_{\mathrm{a}}$ Values in Water and Acetonitrile. Biochim. Biophys. Acta, Bioenerg., 2013, 1827, 882-891.

[9] Kaminski, S.; Daminelli, G.; Mroginski, M. A., Molecular Dynamics Simulations of the Chromophore Binding Site of Deinococcus Radiodurans Bacteriophytochrome Using New Force Field Parameters for the Phytochromobilin Chromophore. J. Phys. Chem. B, 2009, 113, 945-958.

[10] Kaminski, S.; Mroginski, M., Molecular Dynamics of Phycocyanobilin Binding Bacteriophytochromes: A Detailed Study of Structural and Dynamic Properties. J. Phys. Chem. B, 2010, 114, 16677-16686.

[11] Neese, F., The ORCA Program System. Wiley Interdiscip. Rev.-Comput. Mol. Sci., 2012, 2, 73-78.

[12] Breneman, C. M.; Wiberg, K. B., Determining Atom-Centered Monopoles From Molecular Electrostatic Potentials. The Need for High Sampling Density in Formamide Conformational Analysis. J. Comput. Chem., 1990, 11, 361-373. 